\title{
Fusion Safety Program Annual Report Fiscal Year 1994
}

\author{
Glen R. Longhurst \\ Lee C. Cadwallader \\ Thomas J. Dolan \\ J. Stephen Herring \\ Kathryn A. McCarthy \\ Brad J. Merrill \\ Chester G. Motloch \\ David A. Petti
}

Published March 1995

Idaho National Engineering Laboratory Lockheed Idaho Technologies Company Idaho Falls, Idaho 83415

Prepared for the U.S. Department of Energy Office of Energy Research Under DOE Idaho Field Office Contract DE-AC07-94ID13223 


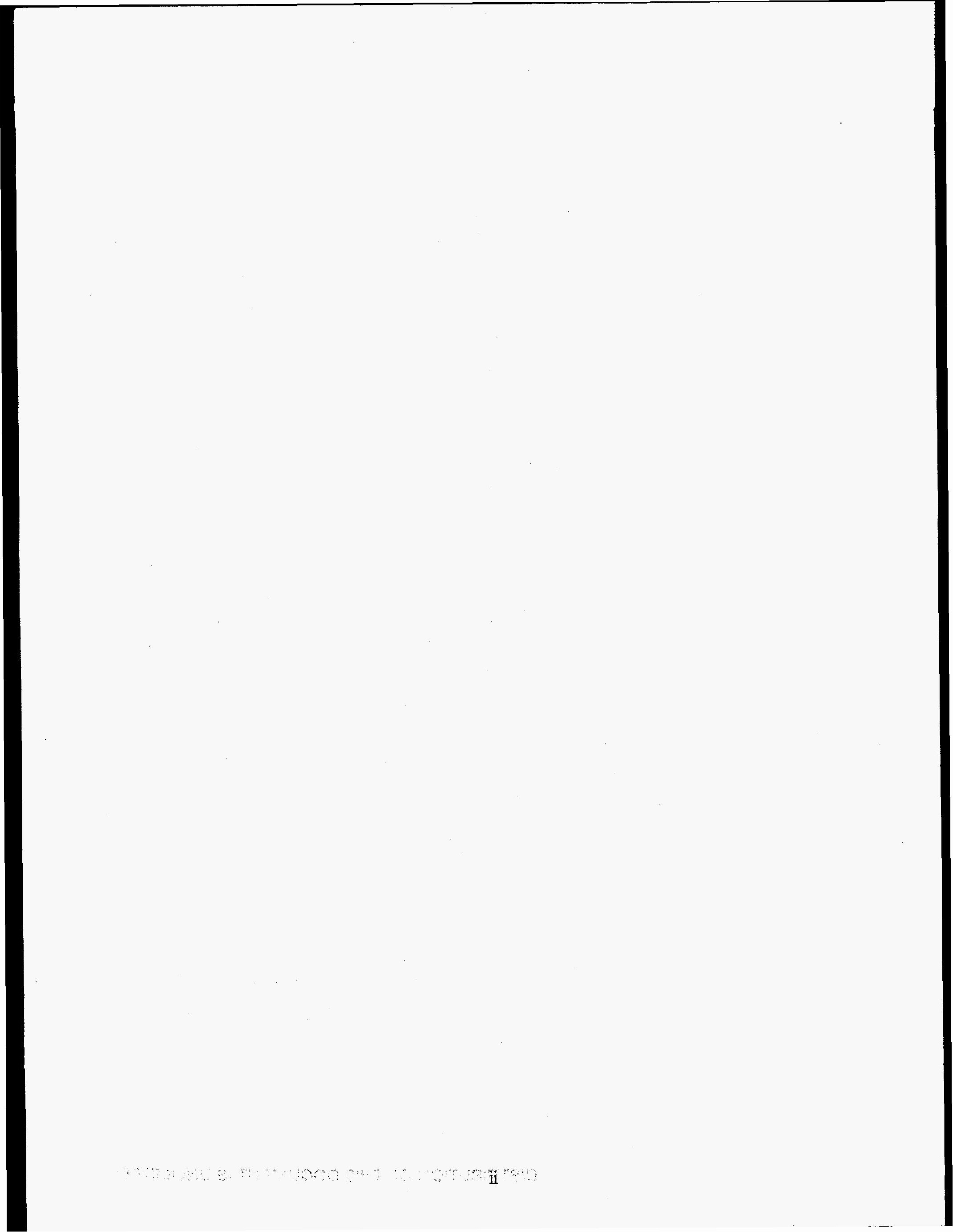




\begin{abstract}
This report summarizes the major activities of the Fusion Safety Program in fiscal year 1994. The Idaho National Engineering Laboratory (INEL) is the designated lead laboratory and Lockheed Idaho Technologies Company is the prime contractor for this program. The Fusion Safety Program was initiated in 1979. Activities are conducted at the INEL, at other DOE laboratories, and at other institutions, including the University of Wisconsin. The technical areas covered in this report include tritium safety, beryllium safety, chemical reactions and activation product release, safety aspects of fusion magnet systems, plasma disruptions, risk assessment failure rate data base development, and thermalhydraulics code development and their application to fusion safety issues. Much of this work has been done in support of the International Thermonuclear Experimental Reactor (ITER). Also included in the report are summaries of the safety and environmental studies performed by the Fusion Safety Program for the Tokamak Physics Experiment and the Tokamak Fusion Test Reactor and of the technical support for commercial fusion facility conceptual design studies. A major activity this year has been work to develop a DOE Technical Standard for the safety of fusion test facilities.
\end{abstract}

\title{
DISCLAIMER
}

This report was prepared as an account of work sponsored by an agency of the United States Government. Neither the United States Government nor any agency thereof, nor any of their employees, makes any warranty, express or implied, or assumes any legal liability or responsibility for the accuracy, completeness, or usefulness of any information, apparatus, product, or process disclosed, or represents that its use would not infringe privately owned rights. Reference herein to any specific commercial product, process, or service by trade name, trademark, manufacturer, or otherwise does not necessarily constitute or imply its endorsement, recommendation, or favoring by the United States Government or any agency thereof. The views and opinions of authors expressed herein do not necessarily state or reflect those of the United States Government or any agency thereof. 


\section{DISCLAIMER}

Portions of this document may be illegible in electronic image products. Images are produced from the best available original document. 


\section{CONTENTS}

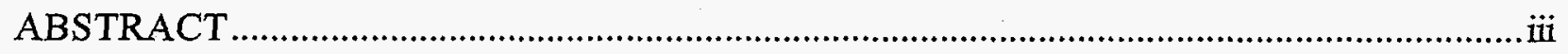

INTRODUCTION

INTERNATIONAL THERMONUCLEAR EXPERIMENTAL REACTOR DESIGN AND

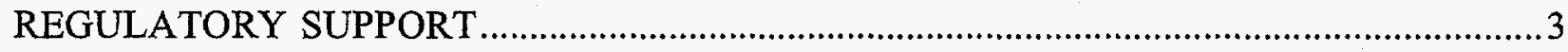

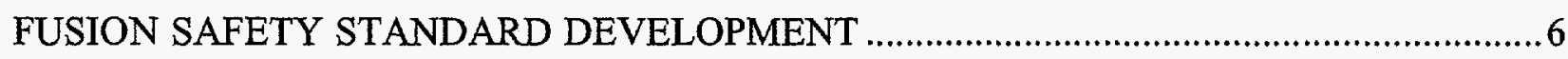

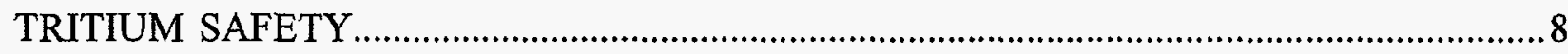

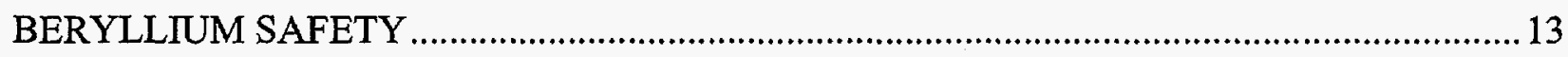

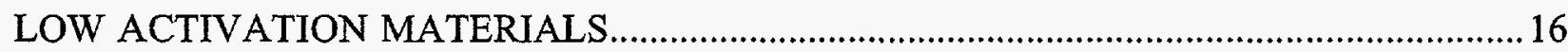

ACTIVATION PRODUCT CHEMICAL REACTIVITY, MOBILIZATION, AND

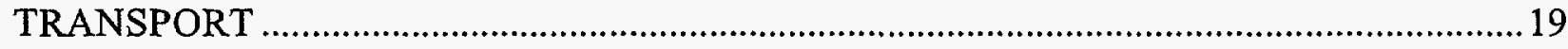

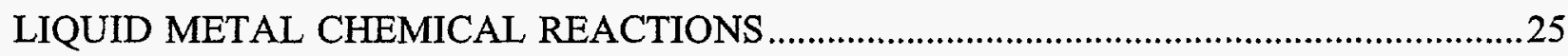

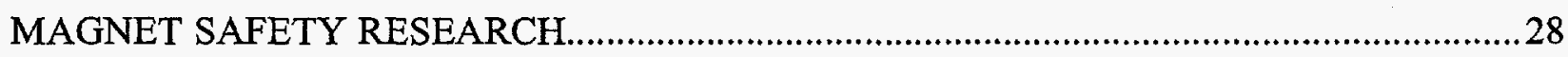

FUSION SAFETY COMPUTER CODE DEVELOPMENT …....................................................

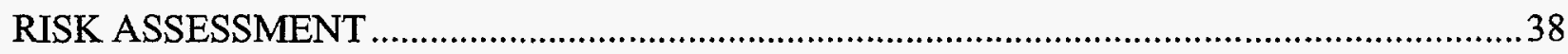

TOKAMAK FUSION TEST REACTOR AND TOKAMAK PHYSICS EXPERIMENT

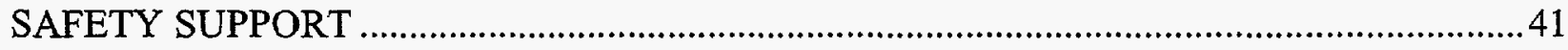

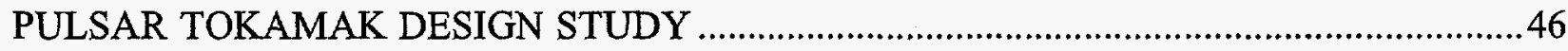

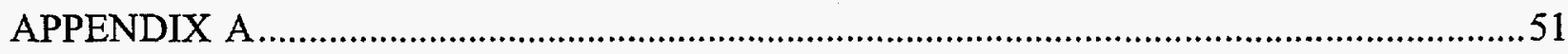

\section{FIGURES}

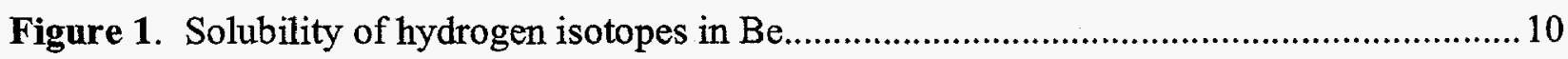

Figure 2. Structure assumed in analyzing tritium inventories in plasma-facing components.

Figure 3. Volatilization of cobalt from PCA Steel is Kinetics Limited.........................................21

Figure 4. ATHENA Nusselt numbers at several Hartmann numbers......................................32 
Figure 5. ITER temperatures during a blanket LOCA.

Figure 6. Schematic of test case accident problem for CONTAIN and MELCOR assessment.

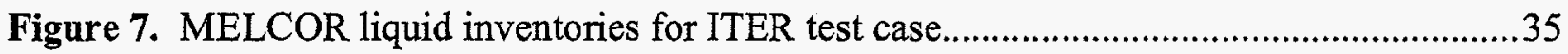

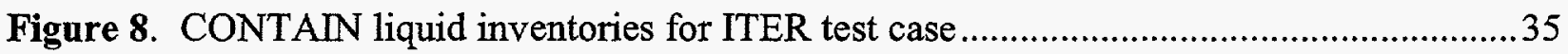

Figure 9. Criteria for safety-significant SSCs per DOE STD-3009-94 _...................................42

\section{TABLES}

Table 1. Confinement release fractions for dry scenarios 22

Table 2. Confinement release fractions for wet/saturated scenarios 23

Table 3. Magnet system faults 28

Table 4. Largest potential radiological doses to the public from TPX accidents.

Table 5. Defense-in-depth and worker safety SSCs 43

Table 6. Results of TPX risk assessment 44 


\section{FUSION SAFETY PROGRAM ANNUAL REPORT FISCAL YEAR 1994}

\section{INTRODUCTION}

Fusion power has the potential to be an important energy source while remaining inherently safe and having attractive environmental features. For the full safety potential to be realized, safety must be considered in all aspects of design and development. In addition to incorporating design features that will enhance the safety potential of fusion systems, we must identify safety and environmental concerns and develop materials and technology required to implement resolutions to those concerns.

In 1979, the U.S. Department of Energy established the Fusion Safety Program to support safety in fusion development. The Idaho National Engineering Laboratory (INEL) is the designated lead laboratory. In 1994, Lockheed Idaho Technologies Company became the prime contractor for the program. The program focus is to develop safety and environmental goals for fusion energy production; to identify potential safety and environmental concerns in fusion devices and approaches to resolve these concerns; and to develop experimental data, technical information, riskassessment methodologies, and safety-analysis computer codes required to verify that fusion facilities are safe and environmentally attractive.

Realization of fusion's potential will result from advances in plasma physics and technology that will enhance safety and environmental attractiveness. Plasma physicists must address issues of plasma disruptions, run-away electrons, emergency plasma shutdown, control of power levels, and reduction of tritium throughput. Priorities in the technology area include developing plasma-facing components, breeding blankets, and coolant materials that are low in activation products and have minimal threats of chemical reactions that could produce explosive quantities of hydrogen. Ultimately, low activation materials will need to be developed for all components and structures exposed to fusion neutrons. The Fusion Safety Program places high emphasis on providing technical support and guidance in these critical areas.

International cooperation has become an increasingly important part of the Fusion Safety Program at the INEL. In addition to participating with Japan, the European Union, and the Russian Federation in the International Thermonuclear Experimental Reactor (ITER) project, we participate in activities of the International Energy Agency.

Activities performed during this fiscal year include conducting experimental tests to develop data needed for safety analysis, developing computer codes and methodology for safety analysis, and participating in studies that support safety in fusion development. The Fusion Safety Program was also involved in safety support for the Tokamak Physics Experiment and the Tokamak Fusion Test Reactor projects at the Princeton Plasma Physics Laboratory. Additionally, the Fusion Safety Program supported the ITER project by commiting two persons to the ITER Joint Central Team and providing analysis and guidance in support of ITER safety studies. Another major activity this year has been to lead the development of a DOE Technical Standard for safety of fusion facilities. 
The following sections summarize work completed under each of these activities by the INEL and participating organizations, including the University of Wisconsin, Oak Ridge National Laboratory, Savannah River Site, Princeton Plasma Physics Laboratory, and Los Alamos National Laboratory.
Broad ITER design studies and programmatic activities appear in the ITER section. More specific ITER work appears under the various technical areas in which the work was performed. Appendix A contains abstracts of publications based on work completed during fiscal year 1994. 


\title{
INTERNATIONAL THERMONUCLEAR EXPERIMENTAL REACTOR DESIGN AND REGULATORY SUPPORT
}

\author{
Researchers: D. A. Petti, J. C. Haire, J. G. Crocker, T. Burr, \\ S. J. Piet, and D. F. Holland-INEL
}

The Fusion Safety Program leads the U.S. safety and environmental effort for the International Thermonuclear Experimental Reactor (ITER). ITER participants are the United States, the European Community, the Russian Federation, and Japan.

As part of the ITER effort, D. F. Holland and S. J. Piet are seconded to the ITER Joint Central Team (JCT). D. F. Holland serves as the Safety Liaison officer at the ITER Naka design site in Japan. S. J. Piet is the Group Leader for Safety Design and Analysis. D. A. Petti is the Task Area Leader for Safety and Standards within the U.S. ITER Home Team.

\section{Major Accomplishments}

This section describes some of the major accomplishments performed as part of our ITER design and regulatory support work. This work was performed under formal ITER tasks agreements between the U.S. and ITER JCT. Additional R\&D work supporting ITER is presented in other sections of this report.

The goal of the work is to provide ITER safety and regulatory support to the JCT and to improve the safety of ITER by identifying key safety issues associated with the evolving ITER engineering design activities.

The United States provided regulatory support to the JCT by writing key sections of their two safety documents: ${ }^{1-5}$ the Early Safety and Environmental Characterization
Study (ESECS) and the General Safety and Environmental Design Criteria (GSEDC). The ESECS document provides early safety assessment information for the four ITER parties to use as they begin siting activities. The GSEDC document is intended to provide overall high-level safety objectives, the safety strategy, and functional safety requirements for ITER. The document serves to communicate this information to both the ITER designers and potential regulatory agencies in the four parties.

Support was also provided to the JCT in the area of structural safety. ${ }^{6}$ Because fusion components will be subjected to environmental conditions that are different than fission reactor components, a process and criteria are needed to select a proper structural code for ITER components. A code selection process was proposed to the JCT and different sections of the ASME Boiler and Pressure Vessel Code were examined to identify the key technical criteria needed in the code selection process for ITER components. This work is continuing in FY-1995.

The U.S. ITER safety team provided substantial support for three major ITER safety and environmental meetings in October 1993, June 1994, and October 1994. All ITER related safety work being performed by the US was reviewed by the ITER JCT at these meetings. The US also provided safety experts to attend and make presentations at the ITER design review in October 1994. 
In addition to providing regulatory information for the ITER JCT, the US ITER Task Area Leader for Safety and Standards made numerous presentations on ITER safety and regulatory issues to US groups such as the ITER Steering Committee US (ISCUS), the US Home, the ITER Industrial Council, and the DOE Office of Fusion Energy.

\section{Future Activities}

Our future efforts will be to continue work in the area of structural safety and to continue work with the JCT on their regulatory and safety strategy for ITER and to help them complete the ESECS and GSEDC safety documents. 


\section{REFERENCES}

1. J. G. Crocker, ITER GSEDC, Section 2, "Basic Safety Characteristics and Safety Functions," ITER/US/94/EN/SA-1, April 1994.

2. J. G. Crocker, ITER GSEDC, Appendix A5-1, "Safety Related Design Requirements for Plasma Operation and Off-Normal Fusion Power Termination," ITER/US/94/EN/SA-2, April 1994.

3. J. G. Crocker, ITER ESECS, Section 1, "Summary," ITER/US/94/EN/SA-3, April 1994.

4. J. G. Crocker, ITER ESECS, Section 3, "Safety Characteristics and Inventories," ITER/US/94/EN/SA-4, April 1994.

5. J. G. Crocker, ITER ESECS, Section 4, "General Safety and Environmental Concept," ITER/US/94/EN/SA-5, April 1994.

6. T. Burr, "Structural Design Safety Guidelines," Section 4.1, ITER/US/EN/SA-8, June 1994. 


\title{
FUSION SAFETY STANDARD DEVELOPMENT
}

\author{
Researchers: G. R. Longhurst, G. A. Dinneen, J. S. Herring, \\ D. A. Petti, C. J. Haire-INEL; D. J. Baker-WSRC; R. V. Carlson- \\ LANL; J. DeLooper-PPPL; M. J. Gouge-ORNL
}

In anticipation of building fusion devices in the U.S., there is a need for a fusion safety document that will serve as the basis for regulatory approval and oversight. This year, activities were initiated to prepare such a document. Initially, it was to appear as DOE Order 5480 FUSION, but in order to meet the aggressive schedule anticipated for ITER site selection and construction, we are preparing it in the form of a Limited Technical Standard, which can later be upgraded to an Order or higher-level directive. Work is proceeding on the document, with the INEL in the leadership role. Various sections are being written by Oak Ridge National Laboratory, Westinghouse Savannah River Company, Princeton Plasma Physics Laboratory, and Los Alamos National Laboratory.

Guidance in preparing the document comes from a Fusion Safety Steering Committee comprising three tiers of participants. The first tier are the regular participants. These persons come from the writers' institutions and from a few others such as the Massachusetts Institute of Technology, Argonne National Laboratory, General Atomics, Raytheon Engineers, \& Constructors, Inc., and Lawrence Livermore National Laboratory. The second tier are ex-officio members, who are all from various offices of DOE, mostly from Headquarters but also from the field offices overseeing the writers' institutions. The final tier are reviewers from stakeholder institutions, including utilities.

\section{Major Accomplishments}

Work this year has been to define require ments for safety in fusion facilities. The Standard will be published in three volumes. Volume I will present requirements. These will be high-level, general requirements and principles. They will leave considerable flexibility on the part of the owner of a fusion facility to determine how to respond to those requirements.

Volume II will contain guidance on how to meet those requirements. Much more extensive than Volume I, Volume II will show a way of meeting the requirements as outlined in current DOE Orders, Standards, and related documents. The guidance is not mandatory in that if the owner of a fusion facility can demonstrate that an alternate approach is equally satisfactory in meeting the requirements of Volume I, that approach may be followed.

Volume III will discuss experience in the design of systems relevant to fusion facilities. Its purpose is to be a technical resource for designers.

In addition to these volumes, a basis and rationale document for Volumes I and II is planned that will provide technical justification for the requirements and guidance.

In FY 1994, we were able to arrive at this document structure and prepare most of the requirements volume, Volume I. Also, we were able to assemble a large part of Volume II. Committee meetings are held quarterly and teleconferences are held monthly to answer questions and resolve discrepancies that arise in the course of the writing. 
Volume I will be distributed to the full Fusion Safety Steering Committee with its supporting Basis and Rationale document early in FY 1995. It will be ready for review throughout the DOE and other stakeholder communities in April. Once comments are received and responded to, it will be ready for approval and issuance. Volume II will also be completed and circulated for review during FY 1995. Volume III will be finished in late FY 1995 or in early FY 1996. 


\section{TRITIUM SAFETY}

\section{Researchers: T. J. Dolan, R. A. Anderl, M. R. Hankins, G. R. Longhurst, R. J. Pawelko, and P. D. Ritter-INEL}

Our tritium safety work focuses on the International Thermonuclear Experimental Reactor (ITER) goals for keeping routine and accidental tritium releases within acceptable limits. We are pursuing a broad spectrum of tritium-related studies, including continued development of the INEL tritium laboratory capabilities; plasma-driven permeation studies for plasma-facing materials (PFM); environmental tritium monitoring around the Tokamak Fusion Test Reactor (TFTR); applications of the TMAP4 code; and participation in the Tritium Plasma Experiment.

\section{Major Accomplishments}

Tritium Research Laboratory. Enhancements were made in the experimental capabilities of the Tritium Research Laboratory. The ion-implantation system was modified to attain higher beam currents on target for sub-keV deuterium ions. This was achieved by modifying the deceleration gap lens to achieve higher beam transmission through the system, and by incorporating the capability to decelerate ions at the target. A new system was developed to provide for thermal desorption mass-spectrometry measurements on samples that have been charged with hydrogen isotopes.

\section{Deuterium Implantation and Permeation} Studies. R. A. Anderl and R. J. Pawelko investigated surface material modifications in beryllium resulting from deuterium implantation at energies ranging from $\mathrm{keV}$ to sub-keV for various specimen temperatures and anneal conditions during the implantation. They used the following techniques to characterize the beam-induced changes and to elucidate the role of these material modifications on deuterium retention and release: (a) surface microstructural and microchemical characteri-zation analyses using Scanning Electron Microscopy (SEM) and depth-profile Auger spectrometry, (b) positron-beam depth profile analyses to characterize defects in unimplanted and deuterium-implanted beryllium, and (c) permeation experiments using sub-keV deuterium ions to complement earlier measurements. A comprehensive report of these studies was prepared for the ITER Joint Central Team. ${ }^{1}$ Specific work related to use of positron-beam analyses was reported at the Fifth International Conference on Hydrogen Effects on Material Behavior. ${ }^{2}$ Highlights from these studies are presented in the following paragraphs.

SEM analyses indicate that the defect generation and evolution in the Be sample highly depended on anneal temperature, specimen temperature during implantation, and beam energy. High-fluence implantation of $1-\mathrm{keV} / \mathrm{D}$ into $\mathrm{Be}$ at temperatures above $623 \mathrm{~K}$ resulted in a surface zone that was highly pocketed and interconnected. For an unannealed specimen, room temperature implantation produced long, oriented blisters. Room-temperature implantation of an annealed specimen created a coarsely textured surface structure with mean dimensions of the features about the size of individual grains. In contrast, implantation of deuterium ions with energies of $330-\mathrm{eV} / \mathrm{D}, 200$ $\mathrm{eV} / \mathrm{D}$, and $100-\mathrm{eV} / \mathrm{D}$ into $\mathrm{Be}$ specimens at temperatures above $715 \mathrm{~K}$ did not result in significant surface structure modification.

Auger depth-profile analyses for $\mathrm{Be}$ specimens revealed differences in surfaceoxide-layer formation and growth that were 
correlated to both the $\mathrm{Be}$ temperature during implantation and to the energy and flux of the implanting deuterium. For high-fluence implantation of $1-\mathrm{keV} / \mathrm{D}$ into $\mathrm{Be}$ at room temperature and temperatures above $723 \mathrm{~K}$, there was no apparent growth in the oxide surface layer beyond that of the native oxide layer ( 3 to $4 \mathrm{~nm}$ ). However, for implantation of hot beryllium with sub-keV deuterium, surface oxide growth was observed.

Positron-beam depth-profile analyses characterized defects in unimplanted and deuterium-implanted beryllium foil specimens for which the anneal temperatures and implantations were varied. Specimens were prepared at the INEL and analyzed at Brookhaven $\mathrm{Na}$ tional Laboratory by K. G. Lynn's research group. Depth-profiles of the defect distributions in the specimens were made by stepping the energy of the positron beam from 0.055 $\mathrm{keV}$ to $40 \mathrm{keV}$, accompanied by the measurements of the Doppler-broadened annihilation radiation line shape at each positron energy. These analyses identified a varying defect structure in beryllium, dependent on the previous anneal history of the implantation with energetic deuterium ions. For specimens implanted at room temperature with $1-\mathrm{keV} / \mathrm{D}$ ions, the beam-induced defect structure had a profile that peaked near the mean range of the implanting deuterium and that extended beyond the implantation zone. Isochronal stepthermal anneal experiments revealed that deuterium was released from these defects at a temperature of about $400 \mathrm{~K}$, indicative of shallow traps, and that the defect structure annealed at temperatures above $623 \mathrm{~K}$. The beam-induced vacancy-defect complexes were estimated to be 1 -nm voids for $1-\mathrm{keV} / \mathrm{D}$ implantation into $\mathrm{Be}$ at room temperature. For beryllium implanted at temperatures of $723 \mathrm{~K}$ with $1-\mathrm{keV} / \mathrm{D}$ ions, these measurements revealed that the beaminduced defect structure was much broader and extended far beyond the implantation zone. Isochronal step-thermal anneal experiments for these specimens revealed a more stable defect structure, with the onset of defect annealing at $775 \mathrm{~K}$. There was no evidence of deuterium release at lower temperatures, indicating that for beryllium implanted at elevated temperatures, deuterium is retained in deep traps; the beam-induced defects most likely consist of large stable voids with defect concentrations less than that for materials implanted at room temperature.

Our work shows that deuterium transport and permeation in ion-implanted beryllium is controlled by both beam-induced defects and by surface oxide layers. In earlier experiments with $1-\mathrm{keV} / \mathrm{D}$ ions, the observation of a delayed, weak permeation signal was attributed to trapping in the beam-induced, surfacemodified zone and to the low permeability of the downstream surface oxide layer. In the experiments for sub-keV deuterium ions, weak permeation was observed for $330-\mathrm{eV} / \mathrm{D}$ and $200-\mathrm{eV} / \mathrm{D}$ ions, but no permeation was observed for implantation with $100-\mathrm{eV} / \mathrm{D}$ ions. There was little delay in the permeation signal, in contrast to that for $1-\mathrm{keV} / \mathrm{D}$. Hence, deuterium trapping at beam-induced defects is not as important for sub-keV/D implantations as for $\mathrm{keV} / \mathrm{D}$ implantations. However, for the sub$\mathrm{keV} / \mathrm{D}$ experiments, oxide layers grew on both the upstream and downstream surfaces. For the lowest energy implants, the deuterium was possibly implanted in the upstream surface oxide. We conclude that surface oxide layers have a major effect on permeation for sub$\mathrm{keV} / \mathrm{D}$ ions.

Tritium Plasma Experiment. INEL collaborated with Los Alamos National Laboratory, Sandia National LaboratoryAlbuquerque, and McDonnell Douglas to write an experimental program plan for Tritium Plasma Experiment. Our activity was lighter than expected in FY 1994, while we waited for glovebox construction and sample holder design. The first plasma was produced in Sep- 
tember 1994, and the TPE should begin regular operations in 1995.

Database Assessment. T. J. Dolan and R. A. Anderl surveyed the literature and compiled an extensive bibliography on tritium interactions with ITER candidate plasma facing materials, including $\mathrm{Be}, \mathrm{C}, \mathrm{Cu}$ and $\mathrm{Cu}$ alloy, $\mathrm{SS}$ and Hastelloy, and $\mathrm{V}$ and $\mathrm{V}$ alloy. ${ }^{3}$ They studied properties of diffusivity, solubility, permeability, chemical reactions, Soret effect, recombination coefficient, surface effects, trapping, porosity, layered structures, interfaces, and oxide effects. They assessed the tritium interaction database and recommended equations for tritium diffusivity and solubility in each material. The hydrogen solubility data for $\mathrm{Be}$ are quite disparate, as indicated in Figure 1.

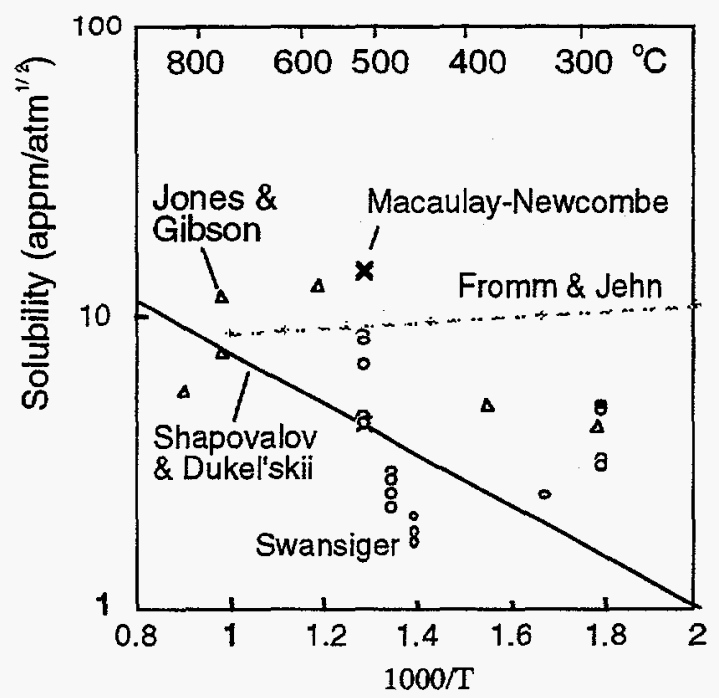

Figure 1. Solubility of hydrogen isotopes in Be.

An understanding of the properties is complicated by oxide film effects, trap sites, impurities, porosity, and multiple forms of the material (especially graphite). Most of the existing database was derived from laboratory experiments that may not fully represent materials in the ITER environment. Additional testing of materials irradiated at high temperatures is needed.
Tritium Source Term Analysis. G. R. Longhurst and T. J. Dolan estimated the invessel tritium source term for the ITER. ${ }^{4}$ The end-of-life inventory comes mainly from tritium breeding in the beryllium by energetic neutrons. Implantation in baffles in the region of the divertor throat and in the upper part of the divertor channel fins is responsible for early inventories. The implanted tritium is expected to reach an atom fraction of about $0.2-0.3$ in the surface layer. The surface oxide layer (Figure 2) will have a dominant effect on the tritium behavior.

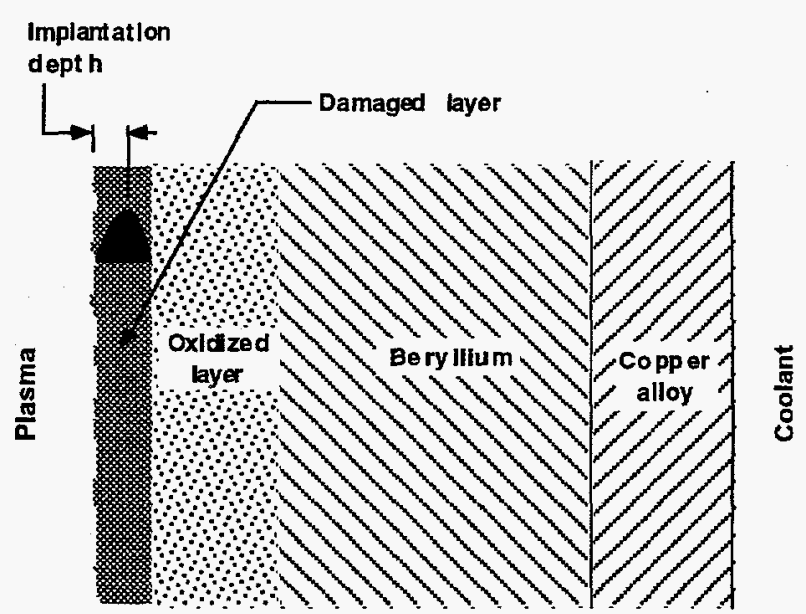

Figure 2. Structure assumed in analyzing tritium inventories in plasma-facing components.

After two years of continuous operation, the bred tritium inventory is $\sim 2.8 \mathrm{~kg}$ (assuming $3 \mathrm{MW}-\mathrm{yr} / \mathrm{m}^{2}$ neutron fluence), and the tritium implantation inventory is estimated to be $\sim 2.2$ $\mathrm{kg}$. If the divertor channel components are changed more frequently, then the tritium inventory would be lower than these values. There is a large uncertainty in these values owing to effects of the layers, pitting, trapping, and impurities.

If the surface temperature were to exceed about $900 \mathrm{~K}$ for several hours, virtually all of the tritium would come out of the beryllium. Preliminary accident analyses indicate that 
temperatures below $773 \mathrm{~K}$ would be expected, so only a few percent of the tritium would be mobilized. If steam reacts with the Be to produce hydrogen, then the tritium emitted would probably be mostly in the elemental (HT) form, but if free oxygen is present, as in the case of air ingress with limited $\mathrm{Be}$ oxidation, then most of the emitted tritium would be oxidized.

\section{Environmental Monitoring at Tokamak} Fusion Test Reactor. P. D. Ritter provided environmental monitoring support at the Tokamak Fusion Test Reactor (TFTR). The purpose of this work was to develop data to characterize environmental transport of tritium over a period of days following a significant tritium release, and to use these data to validate models of environmental tritium transport, such as UFOTRI. We designed and fabricated airborne tritium samplers that could be used to collect continuous sequences of air samples over week-long periods. The samplers are to be deployed within a day of notification of a release. We provided on-site support for maintaining the samplers in a state of readiness.

We compared the results of an UFOTRI model calculation to concentrations measured in the environment around the TFTR following the July 1993 tritium release. We found that the measured and modeled values were in agreement; however, the uncertainties in the meteorological parameters used in the simulation are very large, so this comparison is of limited use for model validation. ${ }^{5}$

TMAP4 Code. T. J. Dolan validated the TMAP4 code for use on a Macintosh computer. ${ }^{6}$ We used this code to estimate the tritium source term in the ITER beryllium first wall for the ITER Early Safety and Environmental Characterization Study (ESECS). As with many finite difference codes, the computational accuracy may be influenced by the combination of mesh size and time step.

We studied tritium implantation in pitted beryllium, using regular features of the TMAP4 code in unconventional ways to represent the existence of pit surfaces and tritium recombination at the pit surfaces. ${ }^{7}$ Study of an example case showed that a $5 \%$ pit area resulted in more than a factor of two reduction of permeation, reduction of mobile inventory, and increase of breakthrough time. Further studies are needed to assess the accuracy of this method.

\section{Future Activities}

In general, our work will be focused to provide support for the Safety and Environmental Tasks of the ITER project.

The tritium laboratory facility upgrade will continue. We will finish studies of deuterium implantation in $\mathrm{Cu}, \mathrm{CuCrZr}$ alloys, and $\mathrm{Be} / \mathrm{Cu}$, and then study other multi-layer materials and/or amorphous mixtures representative of ITER plasma-facing components, in coordination with experiments at the TPE. We will conduct experiments and TMAP4 analyses that complement the experiments at TPE. We will provide equipment and manpower to do thermal desorption spectroscopy of specimens irradiated in TPE and in fission reactors.

We will assess the database for tritium behavior in tungsten. For the ITER source term assessment we will study two alternative designs employing wall coverings of graphite and tungsten.

The TFTR environmental monitoring activities will conclude when the TFTR shuts down at the end of FY-95. 


\section{References}

1. R. A. Anderl, "Deuterium Implantation Studies for Beryllium," ITER/94/US/TE/SA-21 (1994).

2. R. A. Anderl, A. B. Denison, S. Szpala, P. Asoka-Kumar, K. G. Lynn, and B. Nielsen, "Characterization of Defects in Deuterium-implanted Beryllium," Report INEL-94/00036, to be published in the Proceedings of the Fifth International Conference on Hydrogen Effects on Material Behavior, Jackson Lake Lodge, Moran, WY, September 11-15, 1994.

3. T. J. Dolan and R. A. Anderl, "Assessment of Database for Interaction of Tritium with ITER Plasma Facing Materials," ITER/US/94/TE/SA-10, EG\&G Idaho Report EGG-FSP-11348 (September 1994).

4. G. R. Longhurst and T. J. Dolan, "In-vessel Tritium Source Term for ITER," ITER/US/TE/SA-22 (1994).

5. P. D. Ritter, "Post-release Environmental Sampling Program for Acute HT or HTO Releases from the Tokamak Fusion Test Reactor During DT Operations," EG\&G Idaho Engineering Design File FUS-95-001.1, 1994.

6. T. J. Dolan, "TMAP4 Code Use on a Macintosh Computer," EGG Idaho Report EGG-FSP11176, March 1994.

7. G. R. Longhurst, "Modeling Tritium Implantation in Pitted Beryllium," ITER/US/94/TE/SA-7 (May 1994). 


\section{BERYLLIUM SAFETY}

\section{Researchers: G. R. Longhurst, R. A. Anderl, and T. J. Dolan-INEL}

Beryllium is presently contemplated for use in fusion facilities as a plasma-facing material and as a neutron multiplier in tritiumbreeding blanket applications. There are yet several questions regarding the use of beryllium that remain to be answered, many of them connected with safety issues. Some of these issues are the response of beryllium mechanical properties to neutron irradiation, tritium trapping and release characteristics, and the consequences to surface structure of interactions with the plasma. These are among the safety issues we have been investigating. Work on chemical reactions and tritium retention characteristics is addressed in other sections. Here we discuss mechanical property changes and other aspects of safety.

\section{Major Accomplishments}

For several years, we have been investigating the results of neutron irradiation on mechanical properties of beryllium. These properties include strength, ductility, swelling, and hardness. Tests on samples irradiated previously in the Advanced Test Reactor (ATR) have shown that irradiation to high fluence (2.6 $\times 10^{21} \mathrm{n} / \mathrm{cm} 2, E>1 \mathrm{MeV}$ ) at temperatures of about $75^{\circ} \mathrm{C}$ results in a nominally five-fold increase in hardness and strength and a similar decrease in ductility. ${ }^{1}$ We have had samples at densities from 80 to $100 \%$ of theoretical density irradiated in the Fast Flux Test Facility (FFTF) at Hanford, WA and in the Experimental Breeder Reactor (EBR II) at the INEL. These irradiations were conducted at temperatures of 375 to $575^{\circ} \mathrm{C}$ in fast neutron spectra to fluences of $5-6 \times 10^{22} \mathrm{n} / \mathrm{cm}^{2}$. Irradiations in FFTF were completed previously. This year, all the irradiations were completed in the EBRII. The EBR-II samples should be removed from their containers in FY 1995.

G. R. Longhurst participated as a member of a special advisory panel, the DOE Technical Evaluation Panel for the use of Beryllium as Plasma Facing Components and Breeder Blanket Components for ITER. The panel was organized for the DOE Office of Fusion Energy. Its purpose was to evaluate the current state of knowledge and needs for further research on a list of topical areas pertaining to the use of beryllium in ITER. Fusion Safety Program contributions to the findings of this panel were in areas of radiation effects, tritium interactions, health and safety, and chemical interactions with coolants. Findings in these areas are as follows:

Radiation Effects - The response of beryllium to a moderate energy radiation environment such as that in thermal fission reactors is generally well understood. Many of the specific data are for older grades of beryllium rather than for the more modern grades (S-65, HIPed, etc.). No irradiation data exist for plasma-sprayed material. The high neutron energy of ITER raises questions concerning the applicability of much of the existing data. General radiation effects from helium and tritium generation include reduced ductility and associated swelling. Additional experimental data on material irradiated at ITER service temperatures are vitally needed. Some S-200E grade material has been irradiated but not yet evaluated. Initial experiments should focus on differences in results from fast neutron spectra compared with thermal neutron effects already investigated. Also, the effects of neutrons on joints and compliant layers need further study.

Tritium. - Tritium breeding rates in beryl- 
lium will be much higher in a fusion spectrum with a strong 14-MeV component than in a fission spectrum that is strongly thermalized. The amount of bred tritium that remains in the beryllium rather than being released in the operating environment will be influenced by factors such as operating temperature, material density, surface contamination layers, surface roughness, and material porosity. The details of how tritium reemerges to the plasma must be established to predict accumulated tritium inventory and safe operating procedures. This includes not only release at high temperatures but also release when chemical reactions are taking place involving the beryllium. ${ }^{2}$

Health and Safety - A small fraction of the population is capable of being sensitized to beryllium by exposure. Berylliosis or chronic beryllium disease may result when such persons are exposed, especially by inhalation of dusts of beryllium or its compounds. A frequent response of the immune systems of such persons is the deposition of granulomata around the beryllium. This may result in pneumonia-like symptoms and in some cases death. Specific needs are for a means of determining susceptibility to berylliosis and a better means of making real-time measurements of beryllium air concentrations. ${ }^{3}$

Coolant Interactions - ITER designs do not call for beryllium to be in direct contact with coolants because beryllium is not a structural material. However, under accident conditions, hot beryllium exposed to steam can oxidize very exothermically, exacerbating overtemperature conditions and resulting in the generation of potentially explosive quantities of hydrogen. These reactions have a temperature threshold of about $600-800^{\circ} \mathrm{C}$, depending on the condition of the beryllium. Care must be exercised in design and operations to prevent such chemical reactions from taking place. This may be accomplished by providing good heat conduction pathways that will function in all circumstances to remove heat from decay of activation products or chemical reactions. ${ }^{4}$

\section{Future Plans}

We hope to receive the samples from the EBR-II irradiations in mid-calendar 1995. They will be placed in storage, awaiting the receipt of the funding to conduct the tests for which they were designated. It may also be that we will be given direction to conduct chemical reactivity and/or tritium release measurements on some of the samples. The samples that were irradiated in FFTF are still awaiting funding for their removal from their canisters.

Another activity in FY 1995 will be our organizing and holding the 2nd IEA International Workshop on Beryllium Technology for Fusion. This workshop will be held in Jackson Lake Lodge, WY, on September 6-8, 1995. It is a sequel to the meeting held in October 1993 in Karlsruhe, Germany. 


\section{References}

1. J. M. Beeston, G. R. Longhurst, R. S. Wallace, and S. P. Abeln, "Mechanical Properties of Irradiated Beryllium," Journal of Nuclear Materials, 195, pp. 102-108, 1992.

2. G. R. Longhurst and T. J. Dolan, "In-Vessel Tritium Source Term for ITER," ITER/US/TESA-22, October 14, 1994.

3. G. R. Longhurst, "Beryllium Air Concentration Measurement for ITER," ITER/US/94/TE /SA-8, May 23, 1994.

4. W. D. Manly et al., Report of a Technical Evaluation Panel on the Use of Beryllium for ITER Plasma Facing Material and Blanket Breeder Material, Sandia National Laboratories report, to be published. 


\section{LOW ACTIVATION MATERIALS}

\section{Researchers: K. A. McCarthy, M. J. Gaeta, T. J. Dolan, and J. S. Herring-INEL}

Fusion power has the potential to be a safe and environmentally friendly energy source. Through the use of low activation materials, hazards from accidental release of radioactive materials can be limited, and waste disposal problems minimized. ITER will most likely be built from a well-known material such as stainless steel, which is not a low activation material. Thus, parallel to the safety work for materials for ITER, we must look into the safety and environmental aspects of materials that can be used for a demonstration reactor and for commercial power reactors. This task supports work in the safety and environmental aspects of low activation materials.

\section{Major Accomplishments}

We continued work in the area of vanadium recycle. Our primary study looked at the influence of recycling on safety in fusion reactors.

Recycling of radioactive materials is receiving increased attention. Several U.S. universities, national laboratories, and companies in private industry are investigating recycling radioactive materials. Reasons for recycling these materials instead of burying them include the public being adverse to storing radioactive waste and the increasing costs of disposing of radioactive waste. A recent study in Europe by the steel industry and a government laboratory examined the feasibility of recycling steels. ${ }^{1}$ This analysis included all waste streams and radiation exposure to the public and workers at all steps. The economics of recycling low activation steels were shown to be favorable and the technology feasible. Vanadium alloys, because of their low residual activity compared with steels, should be easier to recycle than steels. Cooling times before recycling can be shorter, with less shielding requirements for recycling facilities. It is important to look at the effect of shorter cooling times on safety. With long cooling times such as those assumed by Butterworth, et. al, ${ }^{2}$ the accident hazard does not increase with increasing cycles in the reactor because the shortlived isotopes that dominate accident safety decay to negligible levels during the 75-year cooling time assumed in the study. However, economics may dictate that a shorter cooling time is necessary. The purpose of this study was to look at the effect of shorter cooling times on accident safety

This study showed that recycling the $\mathrm{V}-4 \mathrm{Cr}-4 \mathrm{Ti}$ first-wall material and reusing it does not increase accident hazards. This is because the elements that dominate the accident dose are relatively short lived and decay to insignificant levels during removal from reactor and refabrication. For the same reasons, longer cooling periods do not change accident hazards. However, the effect of the retention factors on accident dose is important to the early and chronic doses. For example, decreasing the $\mathrm{Al}$ content of the alloy during recycling by three orders of magnitude decreases the Na-24 production to insignificant levels, resulting in a lower early dose. Similarly, decreasing the $\mathrm{P}$ content of the alloy by five orders of magnitude decreases the $\mathrm{P}-32$ produc- 
tion, resulting in a lower chronic population dose.

The validity of the retention factors should be investigated. Ideally, this would involve both analytic and experimental work. If the retention factors suggested by Butterworth, et. al. ${ }^{2}$ can be achieved, then impurity levels in the alloy can be decreased from the values assumed in this study. The resulting accident doses would be correspondingly lower.

This study considered only accident safety in the reactor. Accidents in the recycling facilities should also be considered, along with shielding requirements for different cooling periods and number of cycles. Additionally, waste disposal aspects should be considered. Multiple cycles through the reactor could increase the amount of material that must be disposed of as high-level waste.

To move toward understanding retention factors, we worked closely with a group at the
INEL that is carrying out an experimental study of retention factors in $\mathrm{V}-4 \mathrm{Cr}-4 \mathrm{Ti}$, the vanadium alloy currently favored by the United States. Results of this study will be available next fiscal year.

\section{Future Activities}

Work in this area will be minimal due to the pressure to use funds for ITER-relevant work. Our primary effort will support the completion of the experimental study of retention factors in V-4Cr-4Ti. Slag remelting has been chosen as a potential method for processing irradiated vanadium to recover the vanadium for future use. To demonstrate this concept, the INEL and the Bureau of Mines at Albany, Oregon, fabricated five ingots of a V-4Ti-4Cr alloy doped with simulated impurities (manganese, argon, calcium, yttrium) and melted the alloy up to two times each in an electroslag remelt furnace. Results on the effectiveness of this process are forthcoming but preliminary results indicate promising impurity removal capability. 


\section{References}

1. G. R. Gomer, D. Dulieu, K. W. Tupholme, and G. J. Butterworth, "The Feasibility of Recycling Activated Steel First Wall/Blanket Materials from Fusion Reactors," Fusion Engineering and Design, 11, 1990, pp. 423-440.

2. G. J. Butterworth, K. A. McCarthy, G. R. Smolik, and C. B. A. Forty, "Safety and Environmental Aspects of Vanadium Alloys," Journal of Nuclear Materials, 212-215, 1994, pp. $667-673$. 


\title{
ACTIVATION PRODUCT CHEMICAL REACTIVITY, MOBILIZATION, AND TRANSPORT
}

\author{
Researchers: $\quad$ K. A. McCarthy, G. R. Smolik, D. L. Hagrman, D. A. \\ Petti, K. Messick, R. S. Wallace, and A. W. Erickson-INEL
}

Deuterium-tritium $14-\mathrm{MeV}$ fusion neutrons will produce activation products in materials. Since activation products are an accident concern, we examine the behavior of activation products under accident conditions. We study the formation and transport of mobile activation products and chemical reaction rates for potential energy release or hydrogen production. We focus on materials for the divertor, first wall, blanket, and shield, and their behavior at high temperatures during accidents and in oxidizing gases like air and steam

\section{Major Accomplishments}

We have continued developing the database for the mobilization and transport of various elements from candidate materials for the first wall and plasma facing components for ITER and commercial fusion reactors.

Activation Product Mobilization Task. During this fiscal year, the mobilization task focused on four areas: (a) oxidation-driven mobilization experiments with Primary Candidate Alloy steel (similar to $316 \mathrm{SS}$ ), copper alloy, and vanadium alloy, (b) volatility modeling, (c) an assessment of the database, including where more data are needed, and what would be necessary to produce a statistically defensible database, and (d) a scaling study of our experiments on the breakup of mechanically spalled oxides.

Our primary aim in the PCA mobilization tests was to determine Co mobilization. ${ }^{1,2}$
Previous calculations indicated that the mobilization of cobalt isotopes from steel components in ITER would dominate early dose during an accident. These calculations were based on measurements of material collected during exposures of stainless steel samples in air environments. Solutions from these tests were analyzed using inductive coupled plasma-emission spectroscopy (ICP-ES). Results from these tests were constrained by the detection limit of this analytical method. A method using ICP-mass spectroscopy (ICPMS) has been developed with more sensitive capabilities for measuring cobalt. The detection limits that can be obtained by using the ICP-MS are a factor of twenty lower than ICP-ES detection limits. Extending the tests to 100 hours provides an additional reduction factor of about five. Thus, the overall detection limit for cobalt was lowered by a factor of about 100. The detectable flux for this method for a 100 -hour test was about $10^{-7} \mathrm{~g} / \mathrm{m}^{2}-\mathrm{h}$. The temperature range covered in the experiment was 700 to $1200^{\circ} \mathrm{C}$. At $700^{\circ} \mathrm{C}$, the amount of mobilized material coming from the samples was below detection limits; thus, we did not test below this temperature.

The current tests indicate that the doses may be considerably lower than previously calculated if the accident temperatures are generally below $900^{\circ} \mathrm{C}$. For example, about $84 \%$ of the dose (early effective dose) in an airingress accident at a temperature of $600^{\circ} \mathrm{C}$ is due to cobalt isotopes. ${ }^{1}$ Using the current data at $700^{\circ} \mathrm{C}$ (we do not have measurements at 
$600^{\circ} \mathrm{C}$ ) results in doses less than $20 \%$ of the value of the doses calculated with the earlier data. We expect similar results for accidents involving steam (experiments planned for 1995 will measure the mobility of elements other than cobalt in steam).

We measured the mobilization of vanadium, titanium, chromium, scandium, calcium, and manganese from a V-5Ti-5 $\mathrm{Cr}$ alloy when oxidized in air over a temperature range of 600 to $1400^{\circ} \mathrm{C} .{ }^{3}$ The influences of time and heating method upon mobilization rates and more accurate measurements of mobilization rates for calcium and manganese were of primary interest.

In this investigation, the technique used to prepare solutions for analyses was improved, resulting in a reduction in the scatter of the calcium measurements. The detection limit for calcium, as defined by standard deviations from inductive coupled plasma measurements on blank standards, was also lower compared to our FY-93 study. This resulted in consistent calcium measurements significantly above detection limits, even at $600^{\circ} \mathrm{C}$. Calcium mobilization increased substantially from 800 to $1000^{\circ} \mathrm{C}$. The detection limits and measurements of scandium and manganese were similar to those obtained last fiscal year.

In our copper alloy mobilization tests, we concentrated on the effect of composition on mobilization. ${ }^{4}$ The composition of copper changes significantly under irradiation. Compositional changes may affect the extent that various elements are mobilized due to such mechanisms as diffusion through the alloy, and penetration and release from oxide layers formed on the material. We tested three copper alloy compositions with varying amounts of cobalt, nickel, and zinc.
The importance of the composition effect can be seen by comparing doses adjusted for composition with the dose that would result if no adjustment for composition were made. There was about 50 times more cobalt, 8 times more zinc, and 5 times more nickel in one of the sample compositions used in the experiment than is expected in the irradiated first wall of ITER according to activation calculations based on the TAC- 4 design. The calculated dose from cobalt isotopes is about 2 times higher than the dose adjusted for composition for an air ingress accident and about 5 times higher for a water ingress accident. The calculated dose from zinc isotopes is about 3 times higher than the adjusted dose for an airingress accident, and about 7 times higher than for a water ingress accident. The dose from nickel without adjusting for composition is about 2 times too high for both air and wateringress accidents.

Research in the mobilization task has now progressed to the point that it is desirable to have a mechanistic basis to facilitate application of the measurements. Also, modeling provides information on volatility at temperatures where measurements in experiments would be below detection limits. We have produced models for the release of tungsten from tungsten alloy in steam, rhenium from tungsten alloy in air, cobalt and manganese from steels in steam, and sodium from vanadium alloys in air. 5 Figure 3 shows the modeling results compared with experimental results. For this material, the volatilization of cobalt is limited by kinetics, as shown by the better fit to the data; the equilibrium calculation overestimates the volatility significantly.

The general conclusions from the modeling are as follows: 


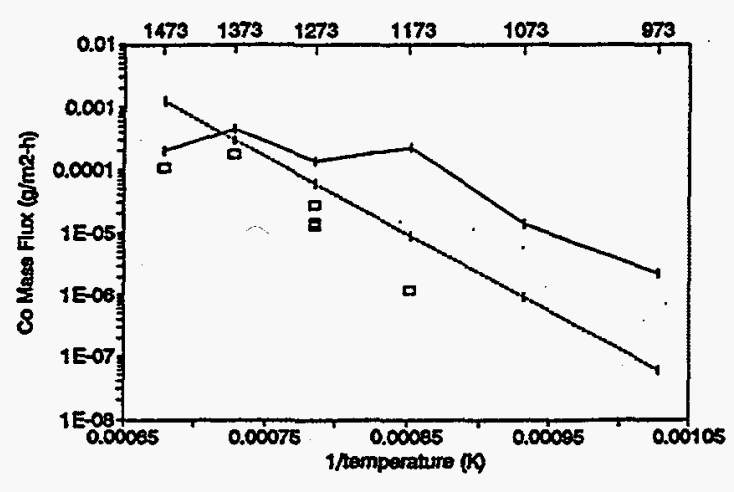

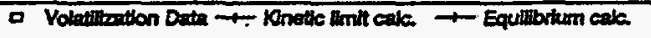

Figure 3. Volatilization of cobalt from PCA steel is kinetics limited.

1. When both equilibrium and reaction rate limits are considered, the model calculations are typically within a factor of 2 or 3 of the measurements, i.e., within the scatter of the measured volatility. Since the models are constructed from first principles rather than fits to the volatility data, the data constitute model validation.

2. Volatilization models require information from the thermal hydraulic analysis of accident scenarios because fluid flow conditions in ITER will affect the rate of volatilization.

3. The chemical species that volatilize from the oxidized surfaces of ITER-relevant materials are often not the surface oxides. Identification of the species that leave the surface is an important part of providing a mechanistic basis for calculations (and, incidentally for correct modeling of the transport of the volatilized material).

4. Volatilization at very low pressure, where the mean free paths of the gas molecules are long, requires different models than volatilization at pressures where the mean free paths are short. Typically, the flux from a surface into a near-vacuum is an order of magnitude more than the flux into gases near atmospheric pressure flowing past the surface.

5. The time-dependent growth of an oxide layer on the surface may affect the mass flux volatilized. Volatilization models for at least some species require information about the growth of oxide layers on surfaces.

The oxides of materials formed during an air or steam-ingress accident, can spall from the surfaces and be carried by convective currents and potentially break up into smaller particles via collision with surfaces. Smaller particles, particularly those that are less than 3- to 5- $\mu \mathrm{m}$ diameter can then be transported through the fusion facility and perhaps to the environment. We carried out a study to scale the results of experiments conducted to measure the breakup of spalled oxides by convective currents. We developed a method to extrapolate the experimental results to ITER ${ }^{6}$. The scaling study indicats that only small quantities of small particles will be produced in ITER; thus, spalled oxide will not contribute significantly to the offsite dose. We will continue our investigation into mechanical spalling to confirm these results.

In preparing data for use in the ITER regulatory process, we assessed our database ${ }^{7}$ and determined what would be necessary to prepare a statistically defensible database. ${ }^{8} \mathrm{Com}$ pilation of a statistically defensible data- base requires multiple tests and analyses at multiple temperatures. We are planning our future tests based on these assessments. 
Aerosol Transport Task. During this fiscal year, the aerosol transport task focused on three areas: (a) development of experiment requirements for a moderate-scale aerosol confinement test facility, (b) calculations of confinement release fractions for aerosols as a function of leak rate, aerosol particle size and mass density, and thermal hydraulic conditions, and (c) transport experiments to measure the particle size of activation products mobilized from a copper alloy and 316 SS.

Experiment requirements for a moderatescale aerosol confinement test facility were prepared. ${ }^{8}$ A review of the information available from aerosol technology indicates that the basic aerosol transport mechanisms in fusion confinements are well known. The principal motivation for constructing a moderate-scale facility is to obtain data to validate aerosol transport models in ITER environments. The distinguishing features of the moderate-scale facility are as follows:

1. It would use aerosol particles that consist of the materials expected in fusion machines.

2. The aerosol volumes and volume-to-surface ratios are larger than those used in laboratory-scale experiments, and would be closer to full-scale.

3. Aerosol particle mass and number densities would span the densities expected in fusion facilities like ITER during accident conditions. In particular, this means the facility must be capable of producing the large total mobilizations that are associated with the rapid volatilization and spalling that may be produced in fusion machines.
We conclude that construction of the full moderate scale facility could be delayed, but work on a technique to generate the large mobilization masses expected during accidents should continue in FY 1995.

First-principle aerosol transport calculations were performed to determine the level of retention and transport in ITER confinement barriers to be used as part of the overall source term methodology for the ITER Early Safety and Environmental Characterization Study.9,10 The results for dry scenarios (air ingress scenarios) indicate that the confinement release fraction depends on the aerosol mass concentration. There was little effect of the temperature and pressure of the air on the results. Based on a conservative estimate of the aerosol concentration expected in an accident $\left(0.1 \mathrm{~g} / \mathrm{m}^{3}\right)$, the confinement release fractions presented in Table 1 are recommended for use in establishing the source term for dry scenarios in Early Safety and Environmental Characterization Study.

Table 1. Confinement release fractions for dry scenarios.

\begin{tabular}{|c|c|c|}
\hline $\begin{array}{l}\text { Confinement } \\
\text { leak rate }\end{array}$ & $\begin{array}{l}\text { Qualitative } \\
\text { confinement } \\
\text { rating }\end{array}$ & $\begin{array}{l}\text { Quantitative } \\
\text { Confinement } \\
\text { Release Fraction }\end{array}$ \\
\hline$\overline{1 \% / \text { day }}$ & Good & 0.01 \\
\hline $10 \% /$ day & Fair & 0.1 \\
\hline $100 \% /$ day & Poor & 1 \\
\hline
\end{tabular}

The results of the wet/saturated scenario analysis indicate that steam condensation plays an important role in determining the subsequent aerosol transport behavior. This condensation generally results in a factor of 100 lower confinement release fraction than dry scenarios for similar initial aerosol mass concentrations. Based on $1 \%$ supersaturated 
steam, the confinement release reactions presented in Table 2 are recommended for use in establishing the source term for wet/saturated scenarios in ESECS.

Table 2. Confinement release fractions for wet/saturated scenarios

\begin{tabular}{lll}
\hline $\begin{array}{l}\text { Confinement } \\
\text { leak rate }\end{array}$ & $\begin{array}{l}\text { Qualitative } \\
\text { confinement } \\
\text { rating }\end{array}$ & $\begin{array}{l}\text { Quantitative } \\
\text { confinement } \\
\text { release fraction }\end{array}$ \\
\hline $1 \% /$ day & Good & 0.0001 \\
$10 \%$ day & Fair & 0.001 \\
$100 \% /$ day & Poor & 0.01 \\
\hline
\end{tabular}

Aerosols formed during exposures of PCA steel and a copper alloy in high temperature and steam were investigated experimentally using the VAPOR apparatus. ${ }^{11}$ Exposures of PCA steel in air resulted primarily in the formation of $\mathrm{MoO}_{3}$ aerosols with particle diameters from 0.2 to $1.5 \mu \mathrm{m}$. A second distribution of particles, probably a mixed spinel, e.g., $(\mathrm{Cr}, \mathrm{Fe}, \mathrm{Ni})_{3} \mathrm{O}_{4}$, with diameters from 1 to $5 \mu \mathrm{m}$ was also present. When the environment was changed to steam, the aerosol mobilized contained a larger fraction of iron and a smaller fraction of molybdenum. The copper alloy produced particles containing copper, nickel, and zinc when exposed in air. At the measurement location, these particles consisted of primary particles with diameters from 0.2 to 1 $\mu \mathrm{m}$ agglomerated to sizes of up to $10 \mu \mathrm{m}$. In steam, the volatilization of zinc from this alloy was much greater than that in air. Also, the primary particles in steam had diameters of only 0.01 to $0.03 \mu \mathrm{m}$. Extensive agglomeration of the particles was observed at the measurement location. These results can be used as input to aerosol transport calculations in safety analysis codes like MELCOR.

\section{Future Activities}

The primary focus of our work will continue to be support of the ITER project. We will issue comprehensive reports on our recent steel, copper alloy, and vanadium alloy tests. Our testing will focus on areas where more data are needed, with a near-term effort directed toward providing data for ESECS. We will begin the design of a moderate-scale aerosol transport facility that will be used to determine deposition and plate-out in fusionrelevant structures such as the vacuum vessel and cryostat. Our initial effort will be in the development of a larger aerosol source for use in the facility. This source could be used in mobilization tests even if the moderate-scale facility is not built (the decision on whether it will be built is up to the ITER JCT). The larger source would result in lower detection limits, allowing us to measure mobilization at lower temperatures than we currently can. We will continue our modeling efforts to support our experimental work. 


\section{References}

1. K. A. McCarthy and G. R. Smolik, "Cobalt Release from PCA Steel," ITER/US/94/TE/SA-5, June 3, 1994.

2. G. R. Smolik, K. A. McCarthy, D. A. Hagrman, and E. B. McNew, "Cobalt Release from PCA Steel During Possible Fusion Reactor Accidents," presented at the 18th Symposium on Fusion Technology, Karlsruhe, Germany, August 22-26, 1994.

3. G. R. Smolik, "Mobilization from a V-5Ti-5Cr Alloy in Air," ITER/US/94/TE/SA-18, September 27, 1994.

4. K.A. McCarthy, G.R. Smolik, R.S. Wallace, and K. Messick, presented at the Third International Symposium on Fusion Nuclear Technology, Los Angeles, California, June 27-July 1, 1994, to be published in Fusion Engineering and Design.

5. D. L. Hagrman, "Volatility Models for Several ITER-Relevant Materials," ITER/94/US/TE/SA-15, September 13, 1994.

6. D. L. Hagrman, "Breakup of Mechanically Spalled Oxides: A Scaling Study," ITER/94/US/TE/SA-14, August 18, 1994.

7. K. A. McCarthy, G. R. Smolik, and S. L. Harms, A Summary and Assessment of Oxidation Driven Volatility Experiments at the INEL and Their Application to Fusion Reactor Safety Assessments, EGG-FSP-11193, September 1994.

8. D. L. Hagrman and D. A. Petti, "Experiment Requirements for a Moderate Scale Fusion Reactor Aerosol Confinement Test Facility," ITER/US/94/EN/SA-9, May 1994

9. D. A. Petti, "Methodology for Estimating The Activation Product Source Term for ESECS," ITER/US/94/EN/SA-6, May 1994.

10. D. A. Petti, "Estimates of Activation Product Transport Through ITER Confinements," ITER/US/94/EN/SA-7, May 1994

11. G. R. Smolik, "Aerosol Characterization for PCA Steel and a Cu Alloy," ITER/US/94/TE/SA19, October 1994. 


\section{LIQUID METAL CHEMICAL REACTIONS}

\section{Researchers: K. A. McCarthy_INEL; L. S. Nelson, J. D. Krueger, G. Vukovic, and M. L. Corradini-UW}

The Liquid Metal Chemical Reactions Program has studied hazards associated with liquid lithium and lithium-lead considered for use as tritium-breeding materials and with various liquid metals considered for use as a coolant. These hazards include hydrogen production, overpressure, and materials volatilization through chemical heat generation.

This task supports both near-term fusion (ITER) and commercial reactors. Liquid metals will be present in the ITER in test modules, with the possibility of their being used as a coolant or breeder in the blanket/first wall.

\section{Major Accomplishments}

The work at the University of Wisconsin this year focused on three major activities. First, we completed the experimental work involving the physical and chemical interaction of water with liquid metal materials that are potential candidates for the divertor in a tokamak fusion reactor design. Second, we initiated and completed a series of scoping experiments that focused on the interaction between molten lithium (a potential breeder material) and a liquid organic (a potential coolant), again for tokamak fusion reactor design considerations. Finally, we were asked to design, and construct an apparatus to manufacture $17 \mathrm{Li} 83 \mathrm{~Pb}$, as well as prepare an initial inventory of the molten metal.

Shock Tube Experiments. We completed the experiments and associated thermodynamic analyses on the interaction of water with mol- ten metals that are candidates for use as divertor materials in the ITER design. ${ }^{1}$ The data and associated analyses indicate that for the materials tested (indium, gallium, lead, tin) the degree of chemical reactivity was minimal. Based on thermodynamic analyses, this was not unexpected. The one minor exception appeared to be indium when it was tested at $600^{\circ} \mathrm{C}$. Under these circumstances, the degree of oxidation was about $10 \%$ for the samples tested. The physical explosions from metal/water heat transfer were also quite mild for these substances. Molten tin was the most energetic, but the energetics when compared to other materials was still small.

\section{Molten Lithium-Organic Coolant} Interactions. Organic coolant has been considered for use in the ITER design with molten lithium. Chemical compatibility was a concern, and we undertook the task of performing experiments to understand this better. Twenty scoping experiments were performed to investigate the behavior of about gram-size molten lithium droplets when released into about a liter of liquid organic coolant (specifically, Therminol 66 coolant) at atmospheric pressure using a unique vortex insertion technique. ${ }^{2}$ Diagnostics consisted of video and photographic imaging, and chemical analyses. Temperature ranges were selected for the organic coolant and the molten lithium drops to represent the extremes in temperature that may be encountered in the operation of the fusion reactor applications, i.e., $470-770 \mathrm{~K}$ for the molten lithium and $300-600 \mathrm{~K}$ for the liquid organic. In none of our experiments was 
there any indication of (a) a vigorous, selfsustaining chemical reaction between the lithium and the organic coolant, or (b) the formation of water insoluble debris, in particular carbon. Our work confirms the benign behavior seen in a limited number of tests reported by other investigators.

Production of Lithium-Lead Alloy. We could not find a U.S. supplier of lithiumlead for use in our lithium-lead/water interaction experiments, so we developed a method to produce the necessary amount. ${ }^{3}$ We devised a technique in which a stainless steel crucible was constructed with a thermocouple and mechanical stirrer as part of its integral design. The lead and lithium constituents were added to the chamber and heated in situ to a steady value $[900 \mathrm{~K}]$ as the mixture was continuously stirred and its temperature was monitored. The chamber was then allowed to cool down and the eutectic composition could be verified by monitoring the phase transition temperature on the cooling curve. Posttest chemical analysis was also done for these crucibles to verify the proper composition. This method of lithium-lead production was superior to any other method previously devised, since each crucible contains a reasonable, 200$\mathrm{cc}$, yet portable amount of the alloy that can be directly reheated and poured out for experimental use.

\section{Future Activities}

We will complete the lithium-lead/water shock tube experiments using the lithium-lead we produced this fiscal year. We will be supporting the ITER project through modifications to the MELCOR computer code. Eventually, this code will be used to evaluate the consequences of liquid metal spills resulting from blanket test module failures. Finally, the Nizhnij Novgorod Polytechnic Institute in Russia will begin a study to look at the removal of bismuth and polonium-210 from lead and lithium-lead. 


\section{References}

1. G. Vukovic, Liquid Metal - Water Interactions in a Shock Tube Geometry, University of Wisconsin Ph.D. Thesis, 1994.

2. L.S. Nelson, J.D. Krueger, and M.L. Corradini, Interactions Between an Organic Coolant and Drops of Molten Lithium, UWFDM-960, June 1994.

3. L.S. Nelson, J.D. Krueger, and M.L. Corradini, Preparation of Kilogram Quantities of the 83 a/o Lead - 17 a/o Lithium Eutectic Alloy, UWFDM-971, November 1994. 


\section{MAGNET SAFETY RESEARCH}

\section{Researchers: J. S. Herring and L. C. Cadwallader-INEL}

Fusion reactors will require large sets of superconducting magnets, storing over $100 \mathrm{GJ}$ of electrical energy. The safe and reliable operation of these magnets is necessary for nearterm experiments and, eventually, for commercial fusion reactors.

Operation of the superconducting magnet system poses a safety concern when a failure such as an arc or structural movement threatens the confinement of radioactive or toxic materials. The Fusion Safety Program aids magnet designers through risk-based analyses that indicate the consequences of individual component failures. These analyses can better ensure the safe discharge of the stored magnetic energy.

\section{Major Accomplishments}

Work on the safety of superconducting magnets focused on the development of a preliminary failure modes and effects analysis for the International Thermonuclear Experimental Reactor (ITER) magnet set during FY-94. In addition, several smaller tasks were performed in support of the ITER Joint Central Team (JCT).

\section{ITER Preliminary Failure Modes and Ef-} fects Analysis. INEL researchers participated in the ITER Magnet and Magnet Safety Technical Meeting at the Naka Joint Work Site in February 1994. A triad Failure Modes and Effects Analysis (FMEA) effort between the Naka Joint Work Site (central solenoid coil), the San Diego Joint Work Site (toroidal field coils) and the INEL (poloidal field coils), was presented at the meeting. In the future, this FMEA should be updated to reflect the changes in the ITER magnet design, which supports the conductors within steel cases around the magnets. Previous ITER designs have supported the conductors in slotted plates.

Because of the size and complexity of fusion magnet systems, failures are to be expected and need to be considered in the design. Designer input regarding initiating events and accident scenarios is very important and useful in realistic safety analyses. Operating data and any failure data harvested from existing coils are helpful for safety analyses for safety documentation and for demonstrating that ITER can be operated reliably and safely. Collecting failure data is an on-going task.

Fault events that have occurred in existing magnet facilities and that are also of potential concern to ITER magnet systems are listed in Table 3.

Table 3. Magnet System Faults.

\section{Magnet Fault Events}

Missiles generation from objects left in magnetic field

Turn-to-turn short circuits

Pancake-to-pancake short circuits

Arcs between leads

Diagnostic lead short circuits

Helium coolant leakage from magnet into insulating vacuum

Unsoldered interturn splices

Conductor strand breakage

Bolts or fasteners loosening from vibration, fatigue, or thermal effects 


\section{Support System Fault Events}

Vacuum insulation jacket inleakage, frozen air or water buildup

Power supply short circuits and fire

Helium compressor failure

Magnet control system faults

Failure rates in the conductors, insulation, isolators, and supporting structures are needed for safety assessment. Data from many disparate sources were used to estimate the failure probabilities.

Other Analysis Tools. A spreadsheet was developed for easy calculation of magnetic fields from a coaxial array of solenoids. This spreadsheet uses the Hastings' approximation $^{2}$ for the elliptic integrals and is being used by the JCT at Naka to estimate occupa tional exposures to magnetic fields during the PF coil cycle. A spreadsheet was also written to quickly determine the adiabatic hot-spot temperature for a variety of conductor configurations.

\section{Future Activities}

We are participating in the safety analysis of the revised ITER magnet set. This analysis, which will be performed in collaboration with the Kernforschungszentrum Karlsruhe, will include the analysis of faults in the power supplies and in the grounding system.

In addition, we are developing tools for estimating the acceleration of ferromagnetic materials in inadvertently placed magnetic field gradients. During some phases of machine operation, these objects might be accelerated toward the reactor, initiating an accident. 


\section{References}

1. L. C. Cadwallader, Magnet Operating Experience Review for Fusion Applications, EGG-FSP9977, Idaho National Engineering Laboratory Informal Report, November 1991.

2. Milton Abramowitz and Irene Stegun, Handbook of Mathematical Functions, Applied Mathematics Series No. 55, National Bureau of Standards, Washington, DC, June 1964, p. 591. 


\section{FUSION SAFETY COMPUTER CODE DEVELOPMENT}

\section{Researchers: K. E. Carlson, M. J. Gaeta, D. L. Hagrman, B. J. Mer- rill, D. A. Petti-INEL; S. C. Jardin-Princeton Plasma Physics Labo- ratory}

Fusion experiments and, eventually, fusion reactors will generate or contain radioactive material in the form of activation products and tritium. These reactors will have a variety of energy sources that can mobilize these materials in several different forms during loss-of-vacuum accidents (LOVAs), lossof-cooling accidents (LOCAs), or plasma disruptions. These energy sources include fusion neutron and particle heat, structure decay heat, plasma stored thermal and magnetic energy, coolant pressurization, chemical reactions, and hydrogen production and possible combustion. The mobilized forms radioactive material can take are (a) dust resulting from plasma-facing-component (PFC) erosion during normal operation, which can contain tritium or activation products; (b) aerosols resulting from structure surface oxidation; (c) aerosols resulting from $\mathrm{PFC}$ erosion during plasma disruptions; (d) isotopic exchange of tritium from PFCs with spilt coolants; and (e) cooling system corrosion products. The extent to which these materials can be confined and, thereby, the amount of radioactive material kept from the environment during LOVAs, LOCAs, and plasma disruptions will depend on the degree to which the integrity of confinement barriers can be maintained.

The objective of this task is to obtain, modify, or develop safety computer codes capable of analyzing these events. Several codes are now being pursued: ATHENA, CHEMCON, DSTAR, and MELCOR. The following paragraphs describe our progress during FY 1994.

\section{Major Accomplishments}

ATHENA. Fusion reactors will require several interacting coolant systems to remove heat from the first wall, blanket, limiter or divertor, and cryogenic superconducting magnets. Different cooling fluids will be used in each of the systems. These separate systems will be interconnected by heat exchangers. To analyze and understand the interactions between these cooling systems, the Idaho National Engineering Laboratory (INEL) is developing a transient analysis code called ATHENA ${ }^{l}$ to simulate both routine and accident conditions.

ATHENA is a nonequilibrium model of the two-phase fluid conservation equations. The ATHENA code is based on the RELAP5/MOD3 code ${ }^{2}$ and is being developed by modifying RELAP5 to include a range of fluids and new constitutive models. ATHENA also includes many generic component models from which general systems can be modeled, such as pumps, valves, pipes, heat structures, electric heaters, jet pumps, turbines, separators, and control system components. In addition, special process models are included for effects such as form losses, flow at abrupt area changes, branches, choked flow, magnetohydrodynamic (MHD) effects, solute tracking, and non-condensable gases.

ATHENA has been developed to analyze conceptual tokamak fusion reactor blanket designs, including those designs that use liquid metals coolants. However, in the past, convective heat transfer correlations valid for water were used for liquid metals. This year, we modified the convective heat transfer model in 
ATHENA to include heat transfer coefficients for liquid metal coolants. ${ }^{3}$

A phenomenon occurs when a conducting fluid, such as a liquid metal, is flowing in a duct with a magnetic field present. ${ }^{4} \mathrm{~A}$ Lorentz force (the cross product of the velocity and magnetic field vectors) is formed and is directed perpendicular to both the velocity and magnetic field. Additionally, an electric field is generated by the conducting liquid flowing through the magnetic field. The interaction of the electric current with the magnetic field causes forces to act on the liquid that flattens out gradients in the velocity profile and dampens flow turbulence. This effect is also known as the Hartmann effect.

The form of the Nusselt number given by Branover ${ }^{4}$ to account for MHD effects is

$N u=\alpha+\beta\left(\psi P e^{\prime}\right)^{\gamma}$

where the modified Peclet number is defined as

$$
P e^{\prime}=\frac{P e}{1+59.2 N}
$$

and where the Stuart number is defined as

$$
N=\frac{\sigma B_{o}^{2} L}{\rho U} .
$$

This modification to the Peclet number accounts for MHD effects. The remaining variables are

$\mathrm{B}_{\mathrm{O}}$ magnetic field (tesla)

$\mathrm{L}$ characteristic length (m)

$\mathrm{N}$ the Stuart number

Pe the Peclet number (Reynolds Prandtl product)

U liquid velocity $(\mathrm{m} / \mathrm{s})$

$\alpha$ the constant for laminar flow $\beta$ an empirically defined coefficient

$\gamma$ an empirically defined exponent

$\rho$ density $\left(\mathrm{kg} / \mathrm{m}^{3}\right)$

$\sigma$ electrical conductivity $(\mathrm{ohm} / \mathrm{m})$

$\psi$ ratio of heat transfer diffusion to momentum diffusion.

We have adopted the empirical coefficients proposed by Subbotin because they represent a best fit to the range of liquid metal heat transfer data available, and because the Subbotin correlation was recommend by Dwyer for fully developed flow in smooth pipes. $^{5}$ The Subbotin correlation is as follows:

$$
N u=5.0+0.025\left(P e^{\prime}\right)^{0.8}
$$

Figure 4 shows the results from an ATHENA calculation. The initial pressure and temperature were $1.0 \times 10^{5} \mathrm{~Pa}$ and $303 \mathrm{~K}$, with fluid velocities increasing from 0 to 79 $\mathrm{m} / \mathrm{s}$. The MHD effect on heat transfer (Nusselt number) as a function of field strength (increasing Hartmann number) can be seen in this figure.

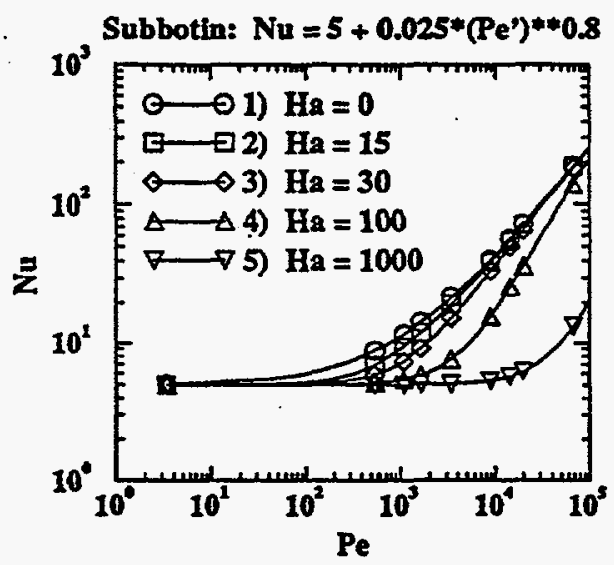

Figure 4. ATHENA Nusselt numbers at several Hartmann numbers.

CHEMCON. A major safety concern investigated in previous studies 6,7 has been the possibility of excessive hydrogen generation re- 
sulting from chemical reactions between the first-wall coating (or armor) and air or steam when the coating is at higher temperatures. Steam may ingress during a LOCA in the blanket cooling system, when the break of this system is within the vacuum vessel. Air may also ingress from failure of a vacuum vessel penetration. The CHEMCON code $^{8}$ has been developed to study these conditions. The CHEMCON code contains a one-dimensional, cylindrical geometry, finite difference conduction model with special models that account for energy generation in the first-wall armor from chemical reactions with air or steam. In addition, it also allows multiple heat transfer modes and heating or cooling to be present in user-specified regions.

This year, a special model was added to the CHEMCON code to simulate the thermal resistance of the thermal radiation shields in ITER. To simulate the thermal resistance, the foils are collapsed to form a solid of equal thickness. Thermal radiation models exist on both sides of this solid component, simulating the radiative resistance of the foils (e.g., radiative heat transfer coefficients are calculated by using the Stefan-Boltzmann law and dividing by the number of foils plus one). During a LOCA when the vacuum vessel temperature rises above $500^{\circ} \mathrm{C}(773 \mathrm{~K})$, the expansion of the vacuum vessel collapses the foils against the toroidal field magnets. The collapsing of the foils is also included in the model.

A parametric study was performed using CHEMCON. The purpose of this study was to determine the accident scenarios that could result in excessive amounts of hydrogen production during a LOCA. Two of the cases studied are believed to be within the design basis for ITER because they include active vacuum vessel cooling, which is a safety system.

Case 1 was performed with vacuum vessel cooling remaining active and an emissivity for the blanket stainless steel of 0.3 . Temperatures remained below $380^{\circ} \mathrm{C}(653 \mathrm{~K})$ with no hydrogen production. Case 2, shown in Figure 5 , is identical to Case 1 with the decay heat multiplied by 1.3. This change causes the first wall peak temperature to rise to $423^{\circ} \mathrm{C}(696 \mathrm{~K})$. Still, hydrogen production was negligible for this case as well. As indicated by these results, design basis accident scenarios that include active vacuum vessel cooling should not produce significant amounts of hydrogen. However, the same cannot be said for the beyond-design-basis scenarios that do not include active vacuum vessel cooling.

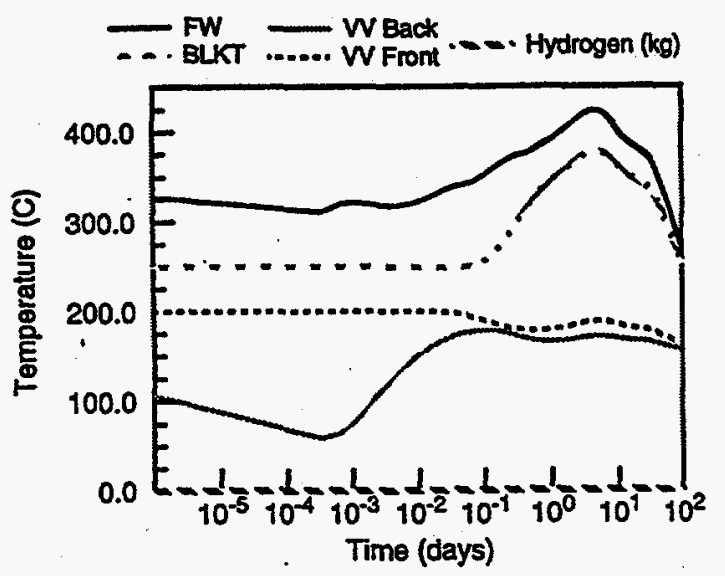

Figure 5. ITER temperatures during a blanket LOCA.

DSTAR. Tokamak plasma disruptions can produce severe structural damage and potentially mobilize tritium, activated dust, and structure activation products. For example, "hard" plasma disruptions rapidly release the plasma magnetic and thermal energy, creating significant protective tile erosion, and induced structural forces. In addition, high loop voltages occur that can generate high-energy runaway electrons. If the generated runaway current is large, these electrons could cause significant first wall and blanket damage when lost from the plasma.

With these issues in mind, the focus of 
this task has been on developing and validating comprehensive models to ensure that proposed reactor designs can safely withstand off-normal plasma events. These models are being added to the Tokamak Simulation Code (TSC), ${ }^{9}$ a tokamak free-boundary plasma physics code under development at the Princeton Plasma Physics Laboratory (PPPL), with the resulting code being called DSTAR. 10 In adopting this approach, we selfconsistently deal with plasma disturbances by accounting for plasma motion, plasma/impurity transport, and induced structural eddy currents.

Significant ablation of the divertor armor material can occur during plasma disruptions. This ablated material forms a partially ionized vapor cloud above the ablating surface, which attenuates the incoming plasma energy. This affect is called vapor shielding. To predict this phenomenon, a scrape-off-layer (SOL) transport model is required that accounts for both the plasma and the ablated material. We added a SOL transport capability to the DSTAR code this fiscal year. The SOL transport model was developed in fiscal year 1993. 11

We tested this new capability for a plasma disruption in ITER with beryllium as the divertor PFC material. Two possible solutions were observed to develop, depending on the predicted transient density of the SOL. For high densities, a high recycling type divertor solution develops in the SOL near the vapor shield, resulting in plasma electron temperatures at the vapor shield of about $10-20 \mathrm{eV}$. For low densities, a low recycling type divertor solution develops in the SOL near the vapor shield, resulting in plasma electron temperatures at the vapor shield of about 8-10 $\mathrm{keV}$. Both solutions are possible depending on the rate at which plasma enters the SOL relative to the rate at which plasma energy is conducted through the SOL. We are planning future studies to validate this finding.

MELCOR. The International Thermonuclear Engineering Reactor (ITER) will contain radioactive material in the form of activation products and tritium. ITER will have a variety of energy sources that can mobilize these materials during hypothetical accidents, such as a LOCA. Two computer codes, MELCOR ${ }^{12}$ and CONTAIN, 13 have been developed for light water fission reactor (LWR) hypothetical accident analyses. Under this task, we assessed these computer codes for application to ITER accident analysis. ${ }^{14}$ We found that both CONTAIN and MELCOR have similar aerosol transport capabilities, but MELCOR has much more sophisticated thermal hydraulic capabilities. Both CONTANN and MELCOR aerosol dynamics models are based closely on the MAEROS model; 15 however, they differ in how water condensation on aerosols is treated. There are significant differences in how fluid flow and heat transfer are modeled, and how the solution scheme is employed to solve the fluid dynamic equations. MELCOR allows for a nonequilibrium treatment of both the liquid and vapor phases of water and for the transport of both phases between computational volumes of the system being modeled. CONTAIN allows for only an equilibrium treatment between the liquid and vapor phases of water, and for only vapor transport between computation volumes of a system being modeled.

As part of our assessment, we developed an ITER-relevant test problem for these codes with the help of ITER Joint Central Team (JCT) safety personnel. This test problem was a hypothetical LOCA resulting from a break at the bottom of the blanket. This break releases water into the plasma chamber and onto the divertor structure, producing an overpressurization of the vacuum vessel and failure of the vacuum ducts, releasing water into the cryostat. 
Figure 6 schematicly depicts how we believe this accident would occur.

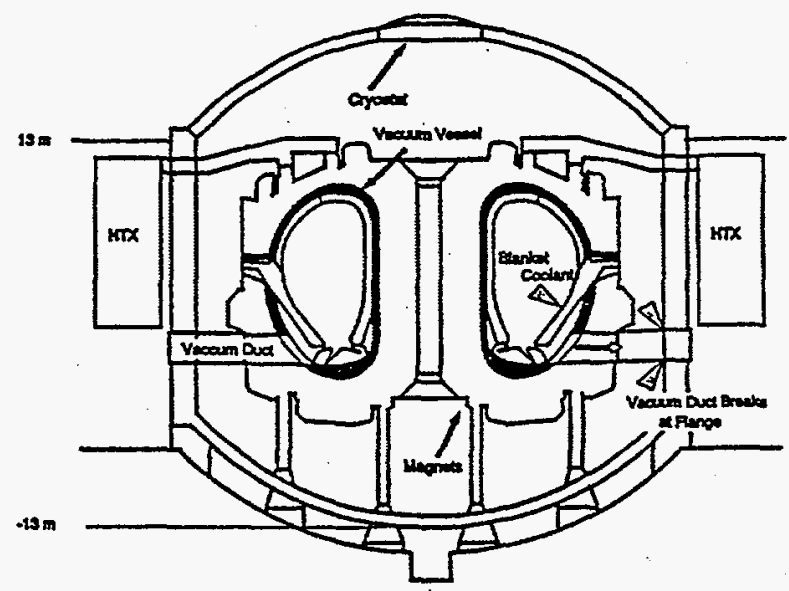

Figure 6. Schematic of test case accident problem for CONTAIN and MELCOR assessment.

The most dramatic difference between the predictions of these codes was for that of predicted liquid inventories. By $1000 \mathrm{~s}$, MELCOR predicts that nearly $60 \%$ of the blanket coolant inventory has left the blanket cooling system, and by 5 hours nearly $70 \%$ of the coolant inventory has left the cooling system. In contrast, CONTAIN predicts that by the end of one day almost $80 \%$ of the coolant inventory still remains within the blanket cooling system. This can be seen by comparing Figures 7 and 8, which contain liquid inventories predicted by MELCOR and CONTAIN, respectively.

Of particular interest with regard to aerosol transport during this accident is the role that diffusiophoresis played in aerosol transport and deposition. Diffusiophoresis is a deposition mechanism that results from condensation of the water vapor onto cold structures, producing a net momentum toward that structure that drags aerosol particles along with it. Most of the aerosol released from within the vacuum vessel during this test case was deposited on the magnet structures by this mechanism.

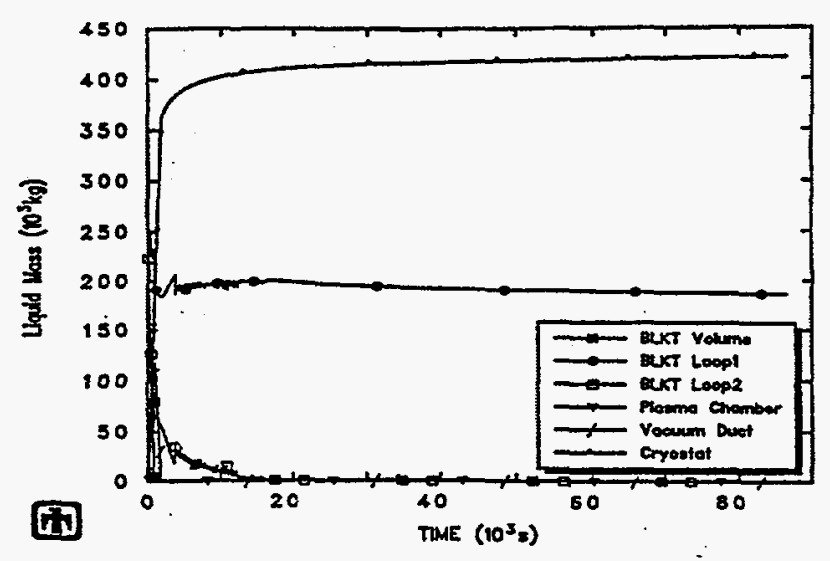

Figure 7. MELCOR liquid inventories for ITER test case.

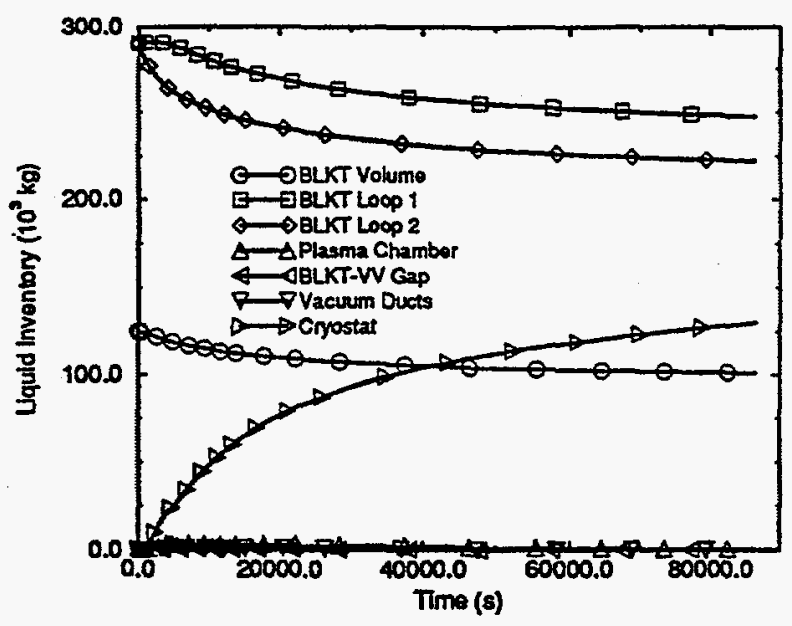

Figure 8. CONTAIN liquid inventories for ITER test case.

Based on this assessment, the MELCOR code was proposed to the ITER JCT as the more accurate tool for analyzing hypothetical accidents in ITER, provided additional modifications were made to this code that account for fusion specific environments. A detailed list of these modifications can be found in Reference 14.

\section{Future Activities}

During the upcoming fiscal year, two major models will be added to the CHEMCON code: a vacuum vessel pressurization and condensation model, and a generic segment model for modeling multiple independent solid struc- 
tures that are coupled through surface thermal radiation. Modifications to MELCOR will be made to treat PFC oxidation and water freezing. In addition, DSTAR validation studies will continue with comparisons being made between predictions and tokamak disruption data. 


\section{References}

1. K. E. Carlson, P. A. Roth, and V. H. Ransom, ATHENA Code Manual, Volume 1 and 2, EGG-RTH-7397, September 1986.

2. C. M. Allison et al., RELAP5/MOD3 Code Manual, Volumes 1, 2, 3, and 4, NUREG/CR5535, EGG-2596, June 1990.

3. K. E. Carlson, Installation and Verification of MHD Effects on Heat Transfer in ATHENA, ITER/US/94/TE/SA-6, April 1994.

4. H. Branover, 1978, Magnetohydrodynamic Flow in Ducts, Israel Universities Press, Jerusalem, pp. 102-104, 234-239.

5. O. E. Dwyer, 1966, Recent Developments in Liquid Metal Heat Transfer, Atomic Energy Review (Austria), 1966, pp. 3-92.

6. B. J. Merrill, "LOCA Temperature/Hydrogen Generation Parametric Study for the ITER CDA Design," ITER/US/93/TE/SA-7, July 1993.

7. M. J. Gaeta, "LOCA Temperature/Hydrogen Generation Parametric Study for the ITER EDA Design," ITER/US/93/TE/SA-17, December 1993.

8. M. J. Gaeta and B. J. Merrill, CHEMCON User's Manual Version 1.1, EGG-FSP-11307, May 1994.

9. S. C. Jardin, N. Pomphrey, and J. Delucia, "Dynamic Modeling of Transport and Positional Control of Tokamaks," Journal of Computational Physics, 66, 1986, p. 481.

10. B. J. Merrill and S. C. Jardin, "DSTAR: A Comprehensive Tokamak Resistive Disruption Model For Vacuum Vessel Components," Fusion Engineering and Design, 5,1987, pp. 235-249.

11. B. J. Merrill and S. C. Jardin, A Description and Application of a Scrape-off-layer Model for the DSTAR Code, ITER/US/93/TE/SA-14, September, 1993.

12. R. M. Summers, R. K. Cole, Jr., E. A. Boucheron, M. K. Carmel, S. E. Dingman, and J. E. Kelly, MELCOR 1.8.0: A Computer Code for Nuclear Reactor Severe Accident Source Term and Risk Assessment Analyses, NUREG/CR-5531 and SAND90-0364, January 1991.

13. K. E. Washington et al., Reference Manual for the CONTAIN 1.l Code for Containment Severe Accident Analysis, NUREG/CR-5715 and SAND91-0835.

14. B. J. Merrill, D. L. Hagrman, M. J. Gaeta, and D. A. Petti, Assessment of CONTAIN and MELCOR for Performing LOCA and LOVA Analyses in ITER, EGG-FSP-11386, September, 1994.

15. Fred Gelbard, MAEROS User Manual, SAND80-0822, NUREG/CR-1391, December 1982. 


\section{RISK ASSESSMENT}

\section{Researchers: L. C. Cadwallader, M. L. Abbott, and A. S. Rood- INEL; T. D. Marshall-Rensselaer Polytechnic Institute}

The Fusion Safety Program (FSP) leads the U.S. effort in using risk assessment in fusion experiment design to provide safety for the public and the environment. Risk assessment is also a part of the design effort for the International Thermonuclear Experimental Reactor (ITER). Two important facets of fusion risk assessment are system analysis and radiological dose assessment. Progress in these facets of fusion risk assessment work in FY 1994 is discussed below.

\section{Major Accomplishments}

System Analysis. INEL researchers supported work on the ITER Early Safety and Environmental Characterization Study (ESECS). The INEL portion of the work focused on invessel accident events. Event trees were constructed for in-vessel loss-of-coolant and lossof-flow events for the various cooling systems that will be used in ITER. ${ }^{1}$ This work was supported by earlier work performed in 1993 and 1994 at the INEL, compiling failure rate data for in-vessel tubing ${ }^{2}$ and vacuum system components. ${ }^{3}$ Consequence assessment for in-vessel events was made easier by work on beryllium reactions that has also been performed at INEL. Most of the in-vessel accident events reside within the unlikely events range (1E-02 to $1 \mathrm{E}-04$ per year), but the small leakage events have been given a higher frequency. Loss-of-flow events were judged to lead to loss-of-coolant events because of the high heat loading that leads to tube wall heating and coolant pressurization. The timing-to-tube failure has a safety impact on plasma shutdown timing, so some initial tests were performed at Sandia National Laboratory in the fall of 1994 to determine a range of times that water-cooled copper divertor tubes (in a copper monoblock design) could survive in normal heat flux (1 to $5 \mathrm{MW} / \mathrm{m}^{2}$ ) conditions under loss of flow. 4 These tests have provided preliminary data that indicate the tubes can only remain intact for times well under 60 seconds. These data will be helpful for future in-vessel safety analysis work.

\section{Dose Consequence Computer Codes.}

The work for this year was a continuation of work from 1993. Radiological dose calculations on Excel spreadsheets for accident releases ${ }^{5}$ and routine effluent releases 6 were completed and sent to the ITER Joint Central Team. These spreadsheets allow quick calculation of doses to help the Joint Central Team to set maximum radioactive inventories for various systems, to help determine the effectiveness needed for confinement functions, and to analyze the consequences of various accident scenarios. In another task that complemented the dose spreadsheet work, INEL researchers performed an initial assessment of the behavior of a simultaneous release of a cryogen and a radioactive effluent. ${ }^{7}$ The results show that nitrogen clouds would sink near the stack base and rise again a few meters away from the base, but helium clouds simply rise.

It is interesting that in September 1994, Dr. G. Kirchner of the Biospheric Model Validation Study (BIOMOVS) research group re- 
quested a copy of the COMIDA (Spanish for food) computerized food-chain model. ${ }^{8}$ COMIDA will be evaluated in a new BIOMOVS assessment of dose calculation computer codes.

\section{Future Activities}

We shall continue to support the ITER Joint Central Team and the U.S. Home Team with risk analysis, including event tree analysis, component failure rate data assessment, and radiological dose assessments. After the ESECS report is completed, attention will focus on supporting the Joint Central Team on the ITER preliminary hazards analysis and preliminary safety analysis reports. One task for radiological dose work is to compile data about dose protocols to explain why certain constants and other fixed values are used for these calculations. This work will help the Joint Central Team to compare dose calculations between the U.S. and Europe. 


\section{References}

1. L. C. Cadwallader, Event Trees for Potential In-Vessel Accident Scenarios in ITER, ITER/US/94/TE/SA-20, September 30, 1994.

2. T. D. Marshall and L. C. Cadwallader, In-Vessel ITER Tubing Failure Rates for Selected Materials and Coolants, EGG-FSP-10928, March 1994.

3. L. C. Cadwallader, Vacuum System Operating Experience Review for Fusion Applications, EGG-FSP-11037, ITER/US/94/TE/SA-18, March 1994.

4. T. D. Marshall, R. D. Watson, L. Cadwallader, J. McDonald, and D. Steiner, Time-toBurnout of An ITER Divertor Tube During a Loss of Flow Accident, ITER/US/94/TE/DV-1, December 5, 1994.

5. M. L. Abbott, S. L. Harms, and A. S. Rood, Dose Calculations for Accidental Airborne Releases of ITER Activation Products, EGG-EEL-10994, ITER/US/94/TE/SA-15, December 1993.

6. M. L. Abbott and D. R. Wenzel, Dose Calculations for Routine Airborne Releases of ITER Activation Products, EGG-EEL-11108, ITER/US/94/TE/SA-19, May 1994.

7. M. L. Abbott, Investigation of Plume Buoyancy Effects During ITER Cryogen Releases, ITER/US/94/TE/SA-13, August 3, 1994.

8. M. L. Abbott and A. S. Rood, "COMIDA: A Radionuclide Food Chain Model for Acute Fallout Deposition," Health Physics, 66 (1), pp. 17-29, 1994. 


\title{
TOKAMAK FUSION TEST REACTOR AND TOKAMAK PHYSICS EXPERIMENT SAFETY SUPPORT
}

\author{
Researchers: C. G. Motloch and R. F. Bonney-INEL; J. C. Com- \\ mander-Consultant; M. A. McKenzie-Carter-SAIC; L. S. Masson- \\ Scientech; and J. D. Levine-PP.PL
}

The Idaho National Engineering Laboratory (INEL) Fusion Safety Program (FSP) continued providing safety support to the Princeton Plasma Physics Laboratory (PPPL). This included completion of the combined Environmental Assessment (EA) for the shutdown and removal of the Tokamak Fusion Test Reactor (TFTR) and for the construction and operation of the proposed Tokamak Physics Experiment (TPX). In addition, we began preparation of the Preliminary Safety Analysis Report (PSAR) for TPX.

TFTR is currently in its last phase of operations and is scheduled for shutdown followed by removal of most of its major hardware. Subsequently, the TFTR facility is planned to be reused to house the TPX. The purpose of TPX is to develop the scientific basis for a compact and continuously operating tokamak fusion reactor. ${ }^{1}$ The TPX design is based on planned deuterium-deuterium (DD) operations, but it does not preclude future deuterium-tritium (DT) operations.

\section{Major Accomplishments}

We completed the combined $\mathrm{EA}^{2}$ for TFTR and TPX, and it has been reviewed and accepted by PPPL, DOE Princeton Area Office, DOE-CH, -ER, -GC, and -EH, and the State of New Jersey. The EA assessed air, water, visual, noise, accident, socioeconomic, chemical, and radiological impacts. It concludes that all impacts were either similar to existing conditions or insignificant. For example, the largest potential radiological doses to the public from TPX accidents are all below regulatory and TPX design objectives. These resulting postulated accident doses are summarized in Table 4.

Table 4. Largest potential radiological doses to the public from TPX accidents.

\begin{tabular}{lcc}
\hline Release & $\begin{array}{c}\text { Individual dose } \\
(\text { rem })\end{array}$ & $\begin{array}{c}\text { Collective dose } \\
\text { (person-rem) }\end{array}$ \\
\hline Tritium & 0.390 & 1,710 \\
Activated gases & 0.001 & negligible \\
Activated solids & 0.005 & 2.2 \\
\hline
\end{tabular}


Based on analyses in the EA, the DOE issued a Proposed Finding of No Significant Impact (PFONSI), which states in part that the DOE believes that the proposed action is not a major Federal action significantly affecting the quality of the human environment within the meaning of the National Environmental Policy Act (NEPA) of 1969, 42 U.S.C. 4321 et seq. The PFONSI will be published in the Federal Register, which will commence a 30-day period for public comment. Following resolution of comments, it is expected that DOE will issue the FONSI, which will complete the NEPA process for TPX.

The second major accomplishment this year was the delivery of the draft TPX PSAR to PPPL. The PSAR is based on assumed DD operations, and it will be revised later if TPX is approved for DT operations.

The TPX PSAR incorporates the graded approach philosophy per DOE-STD-3009-94 ${ }^{3}$ for nonreactor nuclear facilities, but will follow the DOE Order $5480.23^{4}$ twenty-chapter format for nuclear safety analysis reports. For TPX to maintain a less-than-Category-3 Hazard classification per DOE-STD-1027-92 , the tritium inventory will be kept below $1,000 \mathrm{Ci}$ for $\mathrm{DD}$ operations. TPX will have no safety-class systems, structures, or components (SSCs), but may have a few safety-significant SSCs. The criteria for safety-significant SSCs per DOE-STD-300994 are shown in Figure 9, and the criteria for defense-in-depth and worker safety are shown in Table 5.

Does the SSC have a preventive or mitigative function that is a major contributor to defense-in-depth (i.e., prevention of uncontrolled material release) as determined from hazard analysis?

Does the SSC have a preventive or mitigative function that is a major contributor to Worker Safety as determined from hazard analysis?

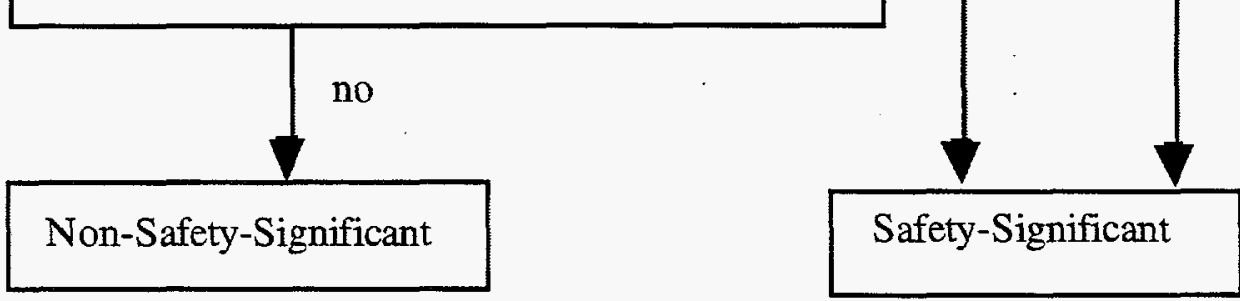

Figure 9. Criteria for safety-significant SSCs per DOE STD-3009-94. 
Table 5. Defense-in-depth and worker safety SSCs.

\begin{tabular}{lll}
\hline & Defense-in-depth SSCs & Worker safety SSCs \\
\hline Includes & $\begin{array}{l}\text { Equipment to prevent or } \\
\text { mitigate accidents leading to } \\
\text { uncontrolled release of haz- } \\
\text { ardous material }\end{array}$ & - $\begin{array}{l}\text { Equipment to prevent or } \\
\text { mitigate acute fatalities or se- } \\
\text { rious injuries }\end{array}$ \\
Excludes & - Administrative features & - Standard industrial hazards \\
& - Safety management \\
programs & - Latent effects \\
\hline
\end{tabular}

The generic list of hazards below was developed for the TPX hazards analysis. The list was screened to eliminate incredible and standard industrial hazards. (Credible is defined as having a frequency of occurrence equal to or greater than $1 \times 10^{-6}$ per year.) The hazards remaining after the screening are chemical exposure, explosion, fire, and ionizing radiation exposure. A risk assessment of these hazards was performed, and the results are summarized in Table 6, which shows that the risks from fire are low for abnormal conditions and accident conditions, and the risk from ionizing radiation is low for normal conditions. All other risks were determined to be negligible. The generic hazards are as follows:

- Aircraft impact

- Chemical exposure

- Compressed gases

- Construction hazards

- Cryogenic hazards

- Electrical hazards

- Explosion

- Fire

- Flammable gases, liquids, and dusts
- Flooding

- High-intensity magnetic fields

- High noise levels

- High winds

- Inadequate illumination

- Inadequate ventilation

- Ionizing radiation exposure

- Low oxygen atmosphere

- Material handling dangers

- Mechanical and moving equipment dangers

- Nonionizing radiation sources

- Seismic events

- Temperature extremes

- Volcanism

- Working at heights.

\section{Future Activities}

We plan to continue support of the safety activities at PPPL, including completion of the Finding of No Significant Impact (FONSI) for the TFTR and TPX EA, and continue development of the TPX PSAR. Upon completion of the TPX PSAR, we plan to begin development of the Final Safety Analysis Report for TPX. 
Table 6. Results of TPX risk assessment.

Risk level (probability x consequence)

\begin{tabular}{lccc} 
Hazard & Normal condition & Abnormal condition & Accident condition \\
\hline Chemical & negligible & negligible & negligible \\
Fire & negligible & low & low \\
Explosion & negligible & negligible & negligible \\
Ionizing radiation & low & negligible & negligible \\
\hline
\end{tabular}




\section{References}

1. Princeton Plasma Physics Laboratory, TPX Conceptual Design Overview, TPX Conceptual Design Review, March 29 - April 1, 1993, 91-930323PPPL/W. Reiersen-01.

2. Environmental Assessment, The Tokamak Fusion Test Reactor Decontamination and Decommissioning Project and the Tokamak Physics Experiment at the Princeton Plasma Physics Laboratory, DOE/EA-0813, May 1994.

3. Preparation Guide for U.S. Department of Energy Nonreactor Nuclear Facility Safety Analysis Reports, DOE-STD-3009-94, July 1994.

4. DOE 5480.23, Nuclear Safety Analysis Reports, April 1992.

5. Hazard Categorization and Accident Analysis Techniques for Compliance with DOE Order 5480.23, Nuclear Safety Analysis Reports, DOE-STD-1027-92, December 1992. 


\section{PULSAR TOKAMAK DESIGN STUDY}

\section{Researchers: J. S. Herring, K. A. McCarthy, and T. J. Dolan-INEL}

During the last six years, the Fusion Safety Program has participated in the ARIES and PULSAR design studies. Other participants in these studies have included the University of California at Los Angeles, San Diego, and Berkeley; the Massachusetts Institute of Technology; the Los Alamos, Argonne, Oak Ridge National Laboratories; General Atomics; and other industrial and utility representatives. The purpose of these studies has been to produce a set of self-consistent commercial designs. In the course of integrating the designs, we have identified the plasma conditions, materials, and reactor configurations necessary to produce a commercially acceptable fusion reactor.

\section{Major Accomplishments}

During FY 1994, we completed the safety analyses of the PULSAR-I and PULSAR-II designs. The PULSAR tokamak reactors have been designed to avoid the use of materials subject to neutron activation and materials that are energy sources for the release of those activation products that are present. These reactors rely on passive safety systems to ensure that they meet safety goals.

PULSAR-I. In PULSAR-I, the coolant is helium, which will not activate and has only the energy stored by its $10 \mathrm{MPa}$ operating pressure. The breeder is lithium oxide, which is also a low activation material that does not chemically react with the containment atmosphere or the coolant. The structure of the first wall, blanket, and shield is silicon carbide, which has a very low neutron activation and is chemically inert. Since the breeder is a lithium compound rather than lithium metal, a neutron multiplier must be used. For the PULSAR-I design, beryllium metal is used for neutron multiplica- tion. Since beryllium metal is combustible, releasing about $60 \mathrm{MJ} / \mathrm{kg}$, the multiplier is the chief source of chemical energy for the release of activation products in the structure. Beryllium oxide would have been preferable from a safety standpoint since that oxide is very inert, but the breeding ratio in the blanket would not be sufficient if a beryllium oxide multiplier were used.

PULSAR-II. The PULSAR-II reactor uses liquid lithium to cool the V-5Cr-5Ti structure. The lithium also serves as the tritium breeder. Using liquid lithium as the breeding blanket material has some safety advantages over solid breeder designs. Among tritium breeders studied by Piet, et al., elemental lithium is the lowest activation breeder, and has low afterheat. Additionally, a multiplier is not necessary in this design, so beryllium, which is toxic and chemically reactive when in the form of beryllium metal, is not needed.

Safety Goals. As with the ARIES-I through ARIES-IV designs, the Level of Safety Assuarance ratings 2,3 were used in evaluating the safety of the PULSAR-I and PULSAR-II designs. These ratings are intimately connected to the costing algorithms used in estimating the eventual cost of electricity (COE) for the reactor design. Our first goal was to achieve an $\mathrm{LSA}=1$ rating.

We feel that the LSA analyses place fusion at a disadvantage with respect to other energy sources, and that in future design studies we should use more mechanistic and credible accident sequences consistent with the evaluation of current technologies.

A second safety goal is to maintain inven- 
tories of radioactive and toxic materials in the plant low enough so that an off-site evacuation plan is unnecessary. A third goal for protecting the public in the long term is all wastes produced by the plant be disposable as Class $\mathrm{C}$ waste in shallow land burial as regulated by 10CFR61. ${ }^{4}$

Public Dose. The radioactive inventory was assumed to be released under conservative (i.e., pessimistic) atmospheric conditions. These same conditions have been used in evaluating all the ARIES and PULSAR designs. We used dose data generated by the FUSCRAC3 code, which is based on the CRAC2 (Calculation of Reactor Accident Consequences) computer code, modified for fusion use. ${ }^{5}$ CRAC, the precursor to CRAC2, was developed for the Reactor Safety Study, WASH-1400. 6 FUSCRAC3 calculates two types of critical doses, a prompt dose and an early dose. The prompt dose is defined as that dose delivered to a particular organ from cloudshine during plume passage, seven days of groundshine, and the dose commitment over the organ-dependent acute time period (two days for whole body) from inhalation during plume passage. The plume passage is equal to the release duration, which is three minutes. The early dose is defined as the dose delivered from cloudshine during plume passage, seven days of groundshine, plus the 50-year dose commitment from radioactivity inhaled during plume passage. Thus, the difference between the prompt and early dose is that the inhalation commitment for the early dose is over a longer period of time.

Recently, most health physics authorities have adopted the Effective Dose Equivalent (EDE) as a measure of radiation exposure. The Fusion Safety Program has also developed tools incorporating this measure. 7,8 However, for consistency in the comparison with earlier ARIES designs, the whole body doses were used in the PULSAR studies.
Public Dose in PULSAR-I. The offsite dose resulting from an accident in the PULSAR-I reactor is dominated by ${ }^{24} \mathrm{Na}$. Sodium is both chemically and biologically active, resulting is a relatively high dose per curie released. Furthermore, since ${ }^{24} \mathrm{Na}$ has a half-life of 15 hours, we cannot assume to decay significantly during its transport out of the reactor and to the site boundary.

The doses to various organs at $1 \mathrm{~km}$ and 10 $\mathrm{km}$ that would result if the entire radioactive inventory of the $\mathrm{SiC}$ outboard first wall were released are dominated by ${ }^{24} \mathrm{Na}$ for all of the organ pathways.

Based on the release fractions calculated for $\mathrm{SiC}$, the prompt offsite whole body dose from a complete LOCA under LSA conditions, which are extremely pessimistic, would be $1.22 \mathrm{~Sv}$; the early dose would be $1.31 \mathrm{~Sv}$.

Public Dose in PULSAR-II. The doses to various organs at $1 \mathrm{~km}$ and $10 \mathrm{~km}$ that would result if the entire radioactive inventory of the $\mathrm{V}$ alloy outboard first wall were released are dominated by ${ }^{48} \mathrm{Sc}$ for most of the organ pathways. ${ }^{48} \mathrm{Sc}$ is a transmutation product, primarily from the alloying element titanium.

The prompt offsite whole body dose from a complete LOCA, under the extremely pessimistic LSA conditions, would be $0.94 \mathrm{~Sv}$, the early dose would be $1.40 \mathrm{~Sv}$.

\section{Future Activities}

We are participating in the safety and licensing task of the STARLITE/DEMO reactor design study. We have suggested requirements and goals in defining the safety objectives for that design. This work is being closely coordinated with the writing of the Fusion Safety Standard at the Idaho National Engineering Laboratory, the Oak Ridge National Laboratory, the Savannah River Laboratory and the Princeton Plasma Physics Laboratory. 
The systems studies task will place special emphasis this year on the development of credible and mechanistic accident sequences. Previous analyses have been based primarily on the inventories, radioactivity, and energy, without determining how that inventory might be released. Furthermore, the previous analyses have given very little credit to aerosol deposition and hindered transport of radionuclides through the reactor building. We generally feel that the LSA analyses place fusion at a comparative disadvantage relative to other energy sources, and that in future design studies we should use more mechanistic and credible accident sequences consistent with current practice in competing technologies. 


\section{References}

1. S. J. Piet, E. T. Cheng, and L. J. Porter, Accident Safety Comparison of Elements to Define Low Activation Materials, EGG-FSP-8552, July 1989.

2. S. J. Piet, "Approaches to Achieving Inherently Safe Fusion Power Plants," Fusion Technology 10, 1986.

3. J. P. Holdren, D. H. Berwald, R. J. Budnitz, J. G. Crocker, J. G. Delene, R. D. Endicott, M. S. Kazimi, R. A. Krakowski, B. G. Logan, and K. R. Schultz, Report of the Senior Committee on Environmental, Safety, and Economic Aspects of Magnetic Fusion Energy, Lawrence Livermore National Laboratory report UCRL-53766, 1989; also, J. P. Holdren, D. H. Berwald, R. J. Budnitz, J. G. Crocker, J. G. Delene, R. D. Endicott, M. S. Kazimi, R. A. Krakowski, B. G. Logan, and K. R. Schultz, "Exploring the Competitive Potential of Magnetic Fusion Energy: The Interaction of Economics with Safety and Environmental Characteristics," Fusion Technology, 13, 1988.

4. S. Fetter, E. T. Cheng, and F. M. Mann, "Long-Term Radioactive Waste from Fusion Reactors: Part II," Fusion Engineering and Design 13, 1990, 239; also, "Standards for Protection Against Radiation," U. S. Nuclear Regulatory Commission, Code of Federal Regulations, Title 10, Parts 0 to $199,1986$.

5. L. J. Porter, Upgrade of a Fusion Accident Analysis Code and Its Application to a Comparative Study of Seven Fusion Reactor Designs, Massachusetts Institute of Technology Report PFC/RR-89-10, June 1989.

6. WASH 1400, Reactor Safety Study, Appendix VI: "Calculation of Reactor Accident Consequences," NUREG 75/014, 1975.

7. M. L. Abbott, S. L. Harms, and A. S. Rood, Dose Calculations for Accidental Airborne Releases of ITER Activation Products, EGG-ELL-10994, December 1993.

8. M. L. Abbott and D. R. Wenze1, Dose Calculations for Routine Airborne Releases of ITER Activation Products, EGG-ELL-11108 (Rev 0), May 1994. 



\section{APPENDIX A}

Summaries of Fusion Safety Program Publications 



\section{TRITIUM SAFETY}

Assessment of Database for Interaction of Tritium with ITER Plasma Facing Materials

T. J. Dolan and R. A. Anderl, EGG-FSP11348, September 1994.

The present work surveys recent literature on hydrogen isotope interactions with $\mathrm{Be}, \mathrm{SS}$, and Inconels, $\mathrm{Cu}, \mathrm{C}$, and $\mathrm{V}$, and alloys of $\mathrm{Cu}$ and $V$. The goals are (a) to provide input to the International Thermonuclear Experimental Reactor (ITER) team to help with tritium source term estimates for the Early Safety and Environmental Characterization Study and (b) to provide guidance for planning additional research that will be needed to fill gaps in the present materials database.

Properties of diffusivity, solubility, permeability, chemical reactions, Soret effect, recombination coefficient, surface effects, trapping, porosity, layered structures, interfaces, and oxides are considered. Various materials data are tabulated, and a matrix display shows an assessment of the quality of the data available for each main property of each material. Recommendations are made for interim values of diffusivity and solubility to be used, pending further discussion by the ITER community.

\section{TMAP4 Code Use on a Macintosh Computer \\ T. J. Dolan, EGG-FSP-11176, March 1994.}

The Tritium Migration Analysis Program MOD1/CY04 (TMAP4) is useful for experimental analysis and for safety studies of the injection, solution, diffusion, trapping, and release of hydrogen isotopes in materials. This code has been verified and validated at
Quality Assurance Level A for use on an IBM PS/2 Model 70 computer operating under DOS 5.0. It is also desirable to validate the TMAP4 code for use on Macintosh computers, since they are used by the International Thermonuclear Experimental Reactor (ITER) project. This report documents the Macintosh IIci computer results from running the same fifteen test cases that were used for validation on an IBM computer. The results on a Mac are very close to those on an IBM, so the validation is demonstrated.

\section{Characterization of Defects in Deuterium- Implanted Beryllium}

R. A. Anderl, A. B. Denison, S. Szpala, P. Asoka-Kumar, K. G. Lynn, and B. Nielsen, INEL-94/00036, September 1994; also in Proceedings of the Fifth International Conference on Hydrogen Effects on Material Behavior, Jackson Lake Lodge, Moran, WY, September 11-15, 1994.

This work investigated surface material modifications in high-purity beryllium foils resulting from $1-\mathrm{keV}$ deuterium ion implantation into specimens for which the anneal temperatures and implantation temperatures were varied. Defects in unimplanted and in deuterium-implanted beryllium were characterized principally by positron-beam depth-profile analysis. Depth profiles of the defect distributions in the specimens were made by stepping the energy of the positron beam from 0.055 $\mathrm{keV}$ to $40 \mathrm{keV}$, accompanied by measurements of the Doppler-broadened annihilation radiation line shape at each positron energy. These analyses identified a varying defect structure in beryllium, dependent on the previous anneal history of the material and on the temperature of the material during implantation with energetic deuterium ions. For specimens implanted 
at room temperature with $1 \mathrm{keV} / \mathrm{D}$ ions, the beam-induced defect structure had a profile that peaked near the mean range of the implanting deuterium and that extended beyond the implantation zone. Isochronal stepthermal anneal experiments revealed that deuterium was released from these defects at a temperature of about $400 \mathrm{~K}$, indicating shallow traps and that the defect structure annealed at temperatures above $623 \mathrm{~K}$. The beam-induced vacancy-defect complexes were estimated to be $1-\mathrm{nm}$ voids for $1-\mathrm{keV} / \mathrm{D}$ implantation into $\mathrm{Be}$ at room temperature. For beryllium implanted at temperatures of $723 \mathrm{~K}$ with $1-\mathrm{keV} / \mathrm{D}$ ions, these measurements revealed that the beam- induced defect structure was much broader and extended far beyond the implantation zone. Isochronal step-thermal anneal experiments for these specimens revealed a more stable defect structure, with the onset of defect annealing at $775 \mathrm{~K}$. There was no evidence of deuterium release at lower temperatures, indicating that for beryllium implanted at elevated temperatures, deuterium is retained in deep traps. These measurements indicate that, for beryllium implanted at elevated temperatures, the beam-induced defects most likely consist of large stable voids with defect concentrations less than those for material implanted at room temperature. 


\section{LOW ACTIVATION MATERIALS}

Vanadium Recycling

T. J. Dolan and G. J. Butterworth, 11th Topical Meeting on the Technology of Fusion Energy, New Orleans, Louisiana, June 19-23, 1994; published in Fusion Technology 26, November 1994, pp. 1014-1020.

Very stringent purity specifications must be applied to low activation vanadium alloys in order to meet recycling goals requiring low residual dose rates after 50-100 years. Following a suitable cooling period after their use, the vanadium alloy components could be melted in a controlled atmosphere to remove volatile radioisotopes. The aim of the melting and decontamination process will be the achievement of dose rates low enough for "hands-on" refabrication of new reactor components from the reclaimed metal. The processes required to permit hands-on recycling appear to be technically feasible, and demonstration experiments are recommended.

\section{Vanadium Recycling}

T. J. Dolan and G. J. Butterworth, EGGFSP-10378, April 1994.

Very stringent purity specifications must be applied to low activation vanadium alloys in order to meet recycling goals requiring low residual dose rates after $50-100$ years. Methods of vanadium production and purification that might meet these limits are described. Following a suitable cooling period after their use, the vanadium alloy components can be melted in a controlled atmosphere to remove volatile radioisotopes. The aim of the melting and decontamination process will be the achievement of dose rates low enough for "hands-on" refabrication of new reactor components from the reclaimed metal. The processes required to permit hands-on recycling appear to be technically feasible, and demonstration experiments are recommended. Background information relevant to the use of vanadium alloys in fusion reactors, including health hazards, resources, and economics, is provided. 


\section{ACTIVATION PRODUCT CHEMICAL REACTIVITY, MOBILIZATION, AND TRANSPORT}

\section{Aerosol Behavior of a Tungsten Alloy For Fusion Reactors}

D. L. Hagrman, G. R. Smolik, D. A. Petti, and K. A. McCarthy, 11th Topical Meeting on the Technology of Fusion Energy, New Orleans, Louisiana, June 19-23, 1994.

The mechanisms involved in the formation and transport of aerosols that might be present during possible fusion reactor accidents were investigated. A cascade impactor was used to collect particles formed by oxidation and volatilization of a tungsten alloy containing $1 \%$ rhenium, an activation product of tungsten. The alloy was tested at 800,1000 , and $1200^{\circ} \mathrm{C}$ in flowing air and at $800^{\circ} \mathrm{C}$ in steam. The quantities, size distributions, and chemical compositions of the particles were determined using a variety of analytical methods. Comparisons were then made with calculations of the vapor release rate, the aerosol nucleation, and the transport of aerosol to the impactor.

\section{Aerosol Characterization for Fusion Reactors}

G. R. Smolik, D. A. Petti, D. L. Hagrman, and K. A. McCarthy, American Nuclear Society Annual Meeting, New Orleans, Louisiana, June 19-23, 1994.

This paper reviews the potential sources and efforts directed toward understanding aerosols in fusion reactors. Aerosol generation in fusion applications has some marked distinctions from those for fission reactors. Releases during severe accident scenarios for fission reactor stem primarily from fission products; both noble gases, e.g., $\mathrm{Xe}$ and $\mathrm{Kr}$, and solids containing isotopes of iodine, cesium, tellurium, etc. The source terms for these elements can be as high as 10 to $100 \%$. By contrast, most activation products formed in fusion reactors are by interactions of the high energy neutrons with first wall and plasma facing components (PFCs). Release from these components can occur from (a) plasma or runaway electron interactions with the PFCs during operation, thus producing erosion products called Tokamak dust, (b) aerosol formed from oxidation and volatilization processes of first wall and PFC materials with air or water intrusion into the plasma chamber during an accident, and (c) small airborne-size particles formed from spalled oxides that may become entrained, and transported, and from various elements from these components, which remain relatively low, i.e., generally less than one percent. This feature coupled with the option to select materials having low activation are the means for optimizing safety for fusion reactors.

\section{The Effect of Composition on Volatility from a Copper Alloy K. A. McCarthy, G. R. Smolik, R. S. Wal- lace, and K. Messick, presented at the Third International Symposium on Fu- sion Nuclear Technology, Los Angeles, California, June 27-July 1,1994, to be published in Fusion Engineering and Design.}

During a Loss-of-Coolant Accident (LOCA), activated structural material can be mobilized through oxidation. Information on how much material is mobilized in an accident is necessary for performing safety assessments of fusion reactor designs. The Fusion Safety Program at the Idaho National Engineering Laboratory has an experimental program to measure mobilized mass as a function of temperature for various oxidizing environ- 
ments. Materials studied have included beryllium (important because of its toxicity), copper alloys, a niobium alloy, austenitic and ferritic steels, tungsten (pure and an alloy), and a vanadium alloy.

Some materials undergo a significant change in composition during irradiation. An example of this is copper (a candidate for the ITER first wall, divertor substrate, and various instrumentation probes and antennas), which can have as much as $1 \mathrm{wt} \%$ zinc due to transmutation. Additionally, as the design for ITER evolves, a slightly different copper alloy may be selected. Compositional changes may affect the extent that various elements are mobilized due to such mechanisms as diffusion through the alloy, and penetration and release from oxide layers formed on the material. To accurately calculate offsite doses for various irradiation scenarios, we must understand the effect of composition on mobilization.

We have carried out a series of experiments in our VAPOR (Volatilization of Activation Products Oxides Reactor) apparatus with a copper alloy containing non-radioactive elements added to represent transmutation products. We prepared samples containing copper, nickel, cobalt, zinc, magnesium, iron, manganese, zirconium, and aluminum. We prepared three different sample compositions with varying amounts of cobalt, nickel, and zinc. We tested the samples in a temperature range from $600-1200^{\circ} \mathrm{C}$ in both air and steam. The species mobilized by volatilization, and oxide spalling are carried downstream and collected in a filter or deposited on the system surfaces. The system components and the filter, consisting of quartz, are chemically cleaned with hydrofluoric acid and processed into solutions that are analyzed. These tests provide a mass flux $\left(\mathrm{g} / \mathrm{m}^{2}-\mathrm{h}\right)$ as a function of temperature for each element.
We used the information from these tests to calculate offsite early doses (for one hour at temperature) as a function of temperature resulting from mobilization of the first wall. We present results for both air and steam exposure. We discuss the effect of copper alloy composition on these doses.

\section{Cobalt Release from PCA Steel During Possible Fusion Reactor Accidents G.R. Smolik, K.A. McCarthy, D.L. Hagrman, and E.B. McNew, 18th Sym- posium on Fusion Technology, Karlsruhe, Germany, August 22-26, 1994.}

Possible accident scenarios for a fusion reactor are breaches in the vacuum or cooling system. Intruding air or stream could then react with structural and plasma facing materials, which would be heated by radioactive decay processes. Safety assessments need to address the amounts of various activation products that could become mobilized during these thermal cycles. Previous calculations show that cobalt isotopes would dominate early dose. Actual measurements of cobalt mobilization during laboratory-scale oxidation experiments had been constrained by the detection limit of the analytical method. A refined method using inductive coupled plasmamass spectroscopy (ICP-MS) has allowed us to reduce this limit by a factor of 100 , i.e., to a flux of $8 \times 10^{-7} \mathrm{~g} / \mathrm{m}^{2}-\mathrm{h}$. Cobalt mobilization has then been measured from PCA steel samples exposed in air and steam between $973 \mathrm{~K}$ and $1473 \mathrm{~K}$.

Cobalt indications above the detection limit occurred at about $1173 \mathrm{~K}$. Flux measurements then increased to $2.5 \times 10^{-7} \mathrm{~g} / \mathrm{m}^{2}-\mathrm{h}$ in air and $1 \times 10^{-3} \mathrm{~g} / \mathrm{m}^{2}-\mathrm{h}$ in steam, respectively, at $1473 \mathrm{~K}$. Mobilization is attributed to two different mechanisms: oxide spalling and vola 
tilization. Small visible pieces of oxides, formed during spalling, were weakly adhered to the quartz walls of the test system. Other, more uniform, deposits on the walls and filter of the test system appeared more typical of those expected from volatilization and aerosol formation processes. The oxide pieces were collected with a water rinse and the deposits removed by acid dissolution. ICP-MS determinations of cobalt after such segregations show that the majority of mobilization resulted from the oxide spalling. The residual amounts reflecting those released by volatilization were compared with predictions from transport theory using vapor pressures of expected volatile species.

This investigation has improved safety implications relative to earlier calculations with regard to the use of 316 stainless steel for ITER. The more accurate measurements from the current investigation, which reflect total mobilization rates, provide lower site boundary dose calculations than those based on earlier detection limits. Furthermore, the majority of the cobalt mobilization, i.e., that resulting from oxide spalling, is quite susceptible to deposition and filtering. A moderatescale aerosol transport facility will provide better indications of amounts of mobilized activation products that would not be, or could be prevented from being, transported and released at site boundaries during an accident.

\section{A Summary and Assessment of Oxida- tion Driven Volatility Experiments at the INEL and Their Application to Fu- sion Reactor Safety Assessments} K. A. McCarthy, G. R. Smolik, and S. L. Harms, EGG-FSP-11193, September 1994.

This report contains a summary and assessment of oxidation-driven volatility tests through March 1994 at the Idaho National Engineering Laboratory. Materials tested include a $\mathrm{Cu}$ alloy in air and steam, PCA stainless steel (similar to 316SS) in air and steam, AMCR-033 steel in air, HT-9 steel in air and steam, a $\mathrm{Nb}$ alloy in air and steam, a W alloy in air and steam, and two $V$ alloys in air with a limited number of tests in steam. We briefly describe the tests, including alloy compositions and test temperatures. For many materials, our results indicate that both volatility and oxide spalling are responsible for mobilizing mass; thus, we refer to our measurements as mass flux or mobility flux. We plot mobility data for each element and present curve fits to the data.

We include a section on use of mobility information in safety assessments. We calculate the early dose inventory of a first wall made of each material tested (the early dose to the maximum exposed person that would result if all the material were mobilized and transported to the site boundary), and the early dose that would result when mobility fractions are considered in the calculation. We use this information to assess the data by determining which elements are the most important and concentrating on providing the mobility data for those elements.

We discuss where more data are needed, and our plans for obtaining that data. Additionally, we discuss what must be done to produce a database that will withstand regulatory scrutiny. 


\section{LIQUID METAL CHEMICAL REACTIONS}

Interactions Between an Organic Coolant and Drops of Molten Lithium

L.S. Nelson, J.D. Krueger, M.L. Corradini, 11th Topical Meeting on the Technology of Fusion Energy, New Orleans, Louisiana, June 19-23, 1994.

Twenty scoping experiments were performed to investigate the behavior of nominally 0.5 -g molten lithium drops when released into $0.7 \mathrm{~L}$ of the organic coolant Therminol 66 at local atmospheric pressure using a vortex insertion technique. Diagnostics consisted of video and photographic imaging and a few chemical analyses. Temperature ranges were selected for the coolant and the Li drops to represent extremes of typical operating conditions being considered for nuclear fusion applications: $\quad 470 \mathrm{~K}<\mathrm{T}_{\mathrm{Li}}<770 \mathrm{~K}$ and $300 \mathrm{~K}<\mathrm{T}_{\mathrm{C}}<600 \mathrm{~K}$. In none of the experiments performed here was there any indication of (a) a vigorous, self-sustaining chemical reaction between the lithium and the organic coolant, or (b) the formation of waterinsoluble debris, in particular, carbon. Our work confirms the benign behavior seen in several experiments reported earlier by others.

\section{Interactions Between an Organic Cool- ant and Drops of Molten Lithium}

L.S. Nelson, J.D. Krueger, M.L. Corradini, UWFDM-960, June 1994; also presented at 11th Topical Meeting on the Technology of Fusion Energy, New Orleans, Louisiana, June 19-23, 1994.

Twenty scoping experiments were performed to investigate the behavior of nomi nally 0.5 -g molten lithium drops when released into $0.7 \mathrm{~L}$ of the organic coolant Therminol 66 at local atmospheric pressure using a vortex insertion technique. Diagnostics consisted of video and photographic imaging and a few chemical analyses. Temperature ranges were selected for the coolant and the Li drops to represent extremes of typical operating conditions being considered for nuclear fusion applications: $\quad 470 \mathrm{~K}<\mathrm{TLi}_{\mathrm{Li}}<770 \mathrm{~K}$ and $300 \mathrm{~K}<\mathrm{T}_{\mathrm{c}}<600 \mathrm{~K}$. In none of the experiments performed here was there any indication of (a) a vigorous, self-sustaining chemical reaction between the lithium and the organic coolant, or (b) the formation of waterinsoluble debris, in particular, carbon. Our work confirms the benign behavior seen in several experiments reported by others.

\section{Preparation of Kilogram Quantities of the 83 a/o Lead - 17 a/o Lithium Eutec- tic Alloy \\ L.S. Nelson, J.D. Krueger, M.L. Corradini, UWFDM-971, November 1994.}

Procedures are given for preparing several kilograms of the $83 \mathrm{a} / \mathrm{o}$ lead $-17 \mathrm{a} / \mathrm{o}$ lithium eutectic alloy for use in melt-water interaction experiments. Both cooling curves and inductively coupled plasma mass spectrometry are used to assess the composition of the alloy.

Because of the high purity of our starting materials and our careful melting procedures, we have determined that the eutectic temperature reported in the literature may be high by as much as $5 \mathrm{~K}$. 


\section{FUSION SAFETY COMPUTER CODE DEVELOPMENT}

LOCA Temperature/Hydrogen Generation Parametric Study for ITER TAC4 Design

M. J. Gaeta, B. J. Merrill, D. A. Petti, Fusion Technology, V 26, 3, Part 2, November 1994.

A parameter study of the transient thermal response of the recent International Thermonuclear Experimental Reactor design was performed for unmitigated loss-of-coolant accidents (LOCAs). Inboard component temperatures and hydrogen production levels remained low for an unmitigated blanket cooling system LOCA. Adding an unmitigated LOCA of the vacuum vessel cooling system to the blanket cooling system LOCA scenario results in much higher first wall temperatures and the production of flammable and, eventually, detonatable amounts of hydrogen in the plasma chamber.

\section{Assessment of CONTAIN and}

MELCOR for Performing LOCA and LOVA Analyses in ITER

B. J. Merrill, D. L. Hagrman, M. J. Gaeta, and D. A. Petti, EGG-FSP-11386, September, 1994.

This report describes the results of an assessment of the CONTAIN and MELCOR computer codes for ITER LOCA and LOVA applications. As part of the assessment, the results of running a test problem that describes an ITER LOCA are presented. We conclude that the MELCOR code should be the preferred code for ITER severe accident thermal hydraulic analyses. This code will require the least modification to be appropriate for calculating thermal hydraulic behavior in ITER relevant conditions that include vacuUm, cryogenics, ITER temperatures, and the presence of a liquid metal test module. Our assessment of the aerosol transport models in these codes indicates that several modifications would have to be made to CONTAIN and/or MELCOR to make them applicable to the aerosol transport part of severe accident analysis in ITER. 


\section{RISK ANALYSIS}

In-Vessel ITER Tubing Failure Rates for Selected Materials and Coolants

T. D. Marshall and L. C. Cadwallader, EGG-FSP-10928, March 1994.

Several materials have been suggested for fabrication for ITER in-vessel coolant tubing: beryllium, copper, inconel, niobium, stainless steel, titanium, and vanadium. This report generates failure rates for the materials to identify the best performer from an operational safety and availability perspective. Coolant types considered in this report are helium gas, liquid lithium, liquid sodium, and water. Failure rates for the materials are generated by including the influence of ITER's operating environment and anticipated tubing failure mechanisms and industrial operating experience failure rates. The analyses define tubing failure mechanisms for ITER as intergranular attack, flow erosion, helium induced swelling, hydrogen damage, neutron irradiation embrittlement, cyclic fatigue, and thermal cycling. K-factors, multipliers, are developed to model each failure mechanism and are applied to industrial operating experience failure rates to generate tubing failure rates for ITER. The generated failure rates identify the best performer by its expected reliability. With an average leakage failure rate of $3.1 \mathrm{e}-10(\mathrm{~m}-\mathrm{hr})^{-1}$ and an average rupture failure rate of $3.1 \mathrm{e}-11$ $(\mathrm{m}-\mathrm{hr})^{-1}$, titanium proved to be the best performer of the tubing materials. The failure rates generated in this report are intended to serve as comparison references for design safety and optimization studies. Actual material testing and analyses are required to validate the failure rates.
Vacuum System Operating Experience Review for Fusion Applications

L. C. Cadwallader, EGG-FSP-11037, March 1994.

This report presents a review of vacuum system operating experiences from particle accelerator, fusion experiment, space simulation chamber, and other applications. Safety relevant operating experiences and accident information are discussed. Quantitative orderof-magnitude estimates of vacuum system component failure rates and accident initiating event frequencies are presented for use in risk assessment, reliability, and availability studies. Safety concerns with vacuum systems are discussed, including personnel safety, foreign material intrusion, and factors relevant to vacuum systems being the primary confinement boundary for tritium and activated dusts. This information should be useful to fusion system designers and safety analysts, such as the team working on the Engineering Design Activities for the International Thermonuclear Experimental Reactor.

\section{Dose Calculations for Accidental Air- borne Releases of ITER Activation Products \\ M. L. Abbott, S. L. Harms, and A. S. Rood EGG-EEL-10994, December 1993}

Radiological dose calculations were performed for $1 \mathrm{TBq}$ atmospheric releases of 534 different radionuclides to support the International Thermonuclear Experimental Reactor (ITER) Engineering Design Activities (EDA). Doses were calculated using a new beta-test version of the MELCOR Accident Consequence Code System (MACCS2), which has 
been revised to evaluate potential accidental impacts at U.S. Department of Energy (DOE) facilities. Three general release and meteorological transport cases were modeled to evaluate two bounding worst-case conditions (with and without rain) and more typical lessconservative conditions. Dose impacts were evaluated for a maximally exposed individual (MEI) member of the public located at $2-\mathrm{km}$ from the release point and for an average population $\left(100 / \mathrm{km}^{2}\right)$ from $2-100 \mathrm{~km}$ from the release point. In addition, ground-level air concentrations normalized to source strength (chi/Q) values were calculated for each radionuclide for 18 distances ranging from 01.-18 $\mathrm{km}$. The chi/Q values are used with the $2-\mathrm{km}$ dose results to estimate relative MEI dose impacts at each of the 18 downwind distances. The dose results and chi/Q values have been incorporated into an electronic spreadsheet program ("scoping tool") that allows a user to quickly retrieve various dose results for selected materials under different release, atmospheric dispersion, and receptor exposure conditions.

\section{Dose Calculations for Routine Airborne Releases of ITER Activation Products M. L. Abbott and D. R. Wenzel, EGG-EEL- 11108 , May 1994.}

Radiological dose calculations were performed for chronic $1 \mathrm{TBq}$ per year atmospheric releases of 656 different radionuclides to support the International Thermonuclear Experimental Reactor (ITER) Engineering Design Activities (EDA). In addition, longterm dispersion factors (chi/Qs) were calculated for each radionuclide for 18 distances ranging from $0.1-18 \mathrm{~km}$. Doses were calculated using a modified version of the Radiological Safety Analysis Computer Program (RSAC-5f) which was expanded for fusion studies to evaluate a larger radionuclide data base. Dose impacts were evaluated for a maximally exposed individual (MEI) member of the public located $2-\mathrm{km}$ from the release point and for an average population $\left(100 \mathrm{~km}^{-}\right.$ 2) from $2-100 \mathrm{~km}$ from the release point. Chi/Qs were determined using the U.S. Environmental Protection Agency's CAP88-PC code and 5 years of meteorological statistics from the Idaho National Engineering Laboratory (INEL). For comparison, chi/Q values were also determined for ten alternative locations in the United States. The chi/Q values can be used to scale $2-\mathrm{km}$ dose results to determine dose impacts at any of the 18 downwind distances. The dose results and chi/Q values have been incorporated into an electronic spreadsheet program ("scoping tool") that allows a user to easily retrieve various dose results for different downwind distances or alternate sites. These results supplement previously published dose calculations for accidental airborne releases of ITER activation products (EGG-EEL-10994 [Rev. 0], December 1993). 